This item was submitted to Loughborough's Research Repository by the author.

Items in Figshare are protected by copyright, with all rights reserved, unless otherwise indicated.

\title{
A synthetic diterpene analogue inhibits mycobacterial persistence and biofilm formation by targeting (p)ppGpp synthetases
}

PLEASE CITE THE PUBLISHED VERSION

https://www.sciencedirect.com/journal/cell-chemical-biology

PUBLISHER

Elsevier

VERSION

AM (Accepted Manuscript)

\section{PUBLISHER STATEMENT}

This paper was accepted for publication in the journal Cell Chemical Biology and the definitive published version is available at https://doi.org/10.1016/j.chembiol.2021.01.018

LICENCE

CC BY-NC-ND 4.0

\section{REPOSITORY RECORD}

Tkachenko, Alexaner G, Natalya Kashevarova, Roman Sidorov, Larisa Nesterova, Anna Akhova, Ivan Tsyganov, Vladimir Vaganov, Sergei Shipilovskikh, Aleksandr Rubtsov, and Andrei Malkov. 2021. "A Synthetic Diterpene Analogue Inhibits Mycobacterial Persistence and Biofilm Formation by Targeting (p)ppgpp Synthetases". Loughborough University. https://hdl.handle.net/2134/13640669.v1. 
1 DMNP, a Synthetic Diterpene Analogue, Reduces Mycobacterial

2 Persistence and Biofilm Formation by Targeting (p)ppGpp

3

4

6

7

Alexander G. Tkachenko,,${ }^{1,}$ Natalya M. Kashevarova, ${ }^{1}$ Roman Yu. Sidorov, ${ }^{1,2}$ Larisa Yu. Nesterova, ${ }^{1,2}$ Anna V. Akhova, ${ }^{1,2}$ Ivan V. Tsyganov, ${ }^{1,2}$ Vladimir Yu. Vaganov, ${ }^{2}$ Sergei A. Shipilovskikh, ${ }^{2}$ Aleksandr E. Rubtsov, ${ }^{2^{*}}$ and Andrei V. Malkov ${ }^{3,4^{*}}$

${ }^{1}$ Laboratory of Microbial Adaptation, Institute of Ecology and Genetics of Microorganisms, Perm Federal Research Center, Russian Academy of Sciences, Ural Branch.

Address: Goleva 13, Perm, 614081, Perm Krai, Russia

${ }^{2}$ Perm State University

Address: Bukireva 15, Perm, 614990, Perm Krai, Russia

${ }^{3}$ Department of Chemistry, Loughborough University Address: University Road, Loughborough, Leicestershire LE11 3TU, UK

${ }^{4}$ Lead Contact

*Correspondence: agtkachenko@iegm.ru (A.G.T.), rubtsov@psu.ru (A.E.R.), a.malkov@lboro.ac.uk (A.V.M.)

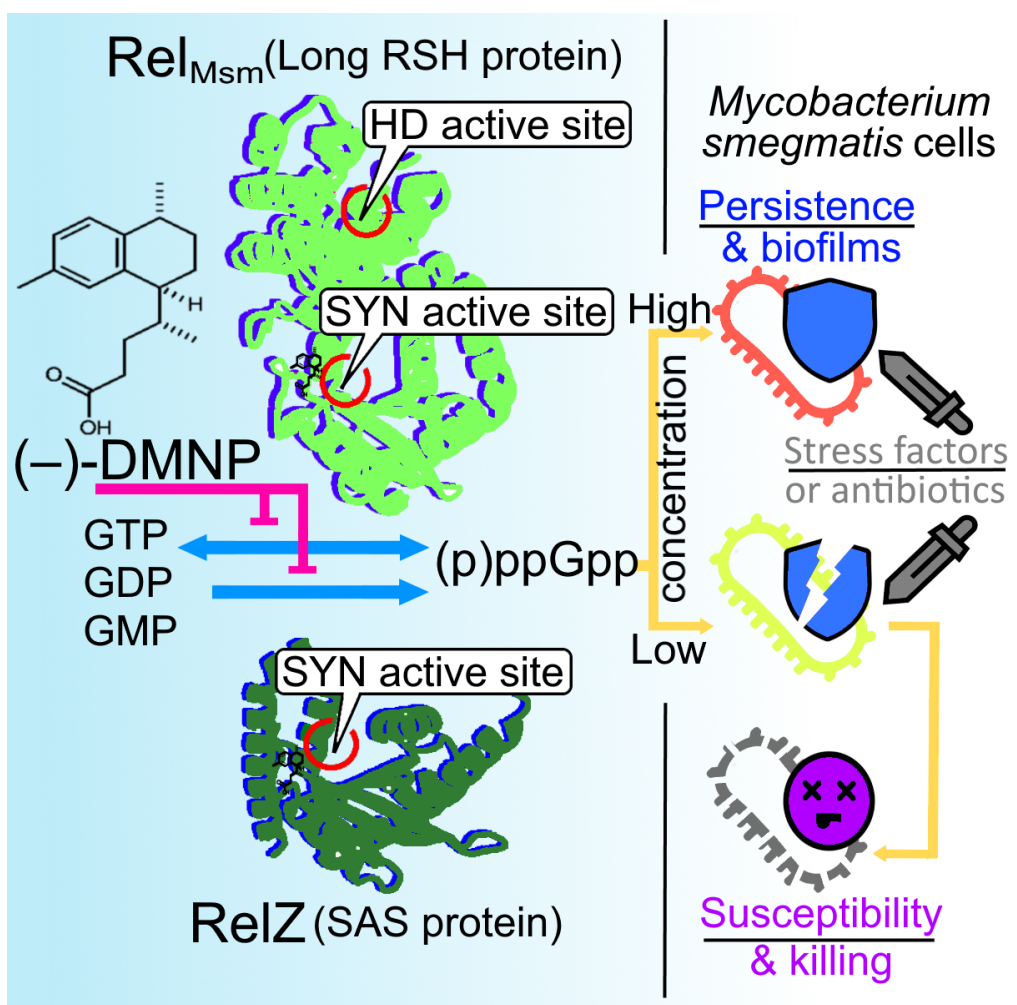

Lead Contact. Further information and requests for responding to material, resources and reagents should be directed to and will be fulfilled by the Lead Contact, Andrei V. Malkov (a.malkov@lboro.ac.uk) 
27 Bacterial persistence coupled with biofilm formation is directly associated with failure of antibiotic treatment of TB. We have now identified 4-(4,7-DiMethyl-1,2,3,4-tetrahydroNaphthalene-1yl)Pentanoic acid (DMNP), a synthetic diterpene analogue, as a lead compound that was capable of suppressing persistence and eradicating biofilms in Mycobacterium smegmatis. By using two reciprocal experimental approaches $-\Delta r e l_{\mathrm{Msm}}$ and $\Delta r e l Z$ gene knockout mutations versus $r e l_{\mathrm{Msm}}$ and relZ overexpression technique - we showed that both Rel $\mathrm{Msm}_{\text {and }}$ RelZ (p)ppGpp synthetases are plausible candidates for serving as targets for DMNP. In vitro, DMNP inhibited (p)ppGpp synthesizing activity of purified Rel $\mathrm{Msm}_{\mathrm{Msm}}$ in a concentration-dependent manner. These findings, supplemented by molecular docking simulation, suggest that DMNP targets the structural sites shared by $\mathrm{Rel}_{\mathrm{Msm}}$, RelZ and presumably by a few others as yet unidentified (p)ppGpp producers, thereby inhibiting persister cell formation and eradicating biofilms. Therefore, DMNP may serve as a promising lead for development of antimycobacterial drugs. 


\section{Introduction}

The rise in antibiotic persistence coupled with biofilm formation is a major health concern directly associated with failure of antibiotic treatment of TB (Esteban and Garcia-Coca, 2017; Sharma et al., 2019). The majority of naturally occurring bacterial cells are thought to be in a dormant or a slow-growing state comparable to stationary phase (Gefen et al., 2014; Kolter et al., 1993) and exhibit high dependence of persister cell formation on (p)ppGpp (Prusa et al., 2018). The latter is a product of stringent factors $\mathrm{Re}_{\mathrm{Mtb}}$ and $\mathrm{Re}_{\mathrm{Msm}}$ for Mycobacterium tuberculosis (Mtb) or Mycobacterium smegmatis respectively (Prossliner et al., 2018; Prusa et al., 2018) that are essential for cell survival during the chronic phase of in vivo infection or stress impacts inducing stringent response (Primm et al., 2000). The absence of (p)ppGpp synthetases in mammalian cells (Mittenhuber, 2001) renders Rel protein an attractive target for developing new antimicrobials to combat bacterial persistence, including tuberculosis. Attempts to chemically synthesize antibiotics structurally similar to (p)ppGpp such as its analog relacin (Wexselblatt et al., 2012) had limited success (Prusa et al., 2018). Therefore, the identification of new inhibitors of (p)ppGpp synthesis is important for developing effective antitubercular medication.

We synthesized a variety of derivatives of erogorgiaene (Incerti-Pradillos et al., 2016), of which 4-(4,7- DiMethyl-1,2,3,4- tetrahydroNaphthalene-1-yl)Pentanoic acid (DMNP) emerged as the most active lead compound targeting mycobacterial persister cell formation. We now endeavored to identify the DMNP target(s) in mycobacterial cells and to elucidate its mechanism of action. Fast growing M. smegmatis that shares phenotypic and genetic similarities with Mtb was employed as a model organism (T et al., 2020). Batch cultures of this organism were used as a convenient tool for modeling persister cell formation during transition to stationary phase.

The findings of this study strongly support our hypothesis that DMNP targets the structural sites shared by mycobacterial Rel $\mathrm{M}_{\mathrm{Msm}}, \mathrm{RelZ}$ and possibly by some other as yet unidentified (p)ppGpp producers, thereby inhibiting persister cell formation and eradicating biofilms. Therefore, 
75 infections.

76

77 Keywords: diterpene, synthetic analogue, mycobacteria, persistence, biofilm formation, target, $78 \quad$ Rel $_{\text {Msm, RelZ, (p)ppGpp synthetases }}$

79

80

81

82

83

84

85

86

87

88

89

90

91

92

93

94

95

96 


\section{Results}

\section{Synthesis}

The stereoselective synthesis of (-)-4-(4,7-dimethyl-1,2,3,4-tetrahydronaphthalene-1yl)pentanoic acid (DMNP, 2), an analogue of natural marine diterpene erogorgiaene 1, is shown in Figure 1.

\section{Cell Killing Activity of DMNP Is Potentiated in Standing Cultures of M. smegmatis}

Activities of antibiotics currently used in clinical practice against M. smegmatis cells were compared at different growth phases (Figure 2A) with the activity of DMNP (2, MW=260.38), a derivative of erogorgiane $(\mathbf{1}, \mathrm{MW}=270.50)$ (Figure 1, Figure 2B). Importantly, when $M$. smegmatis cells entered the stationary phase, there was an increase in the number of cells tolerant to the conventional clinical antibiotics tested, whereas DMNP decreased the number of survivor cells by more than 4-5 orders of magnitude (Figure 2C). Thus, it is reasonable to hypothesize that some target(s) specific for DMNP emerged in the cells in this period. Reduced energy state observed in these cells (Figure 2D) appears to be among the main reasons behind the deceleration of the growthassociated processes targeted by most of the clinical antibiotics, thus resulting in quiescent state and persister formation (Brauner et al., 2016; Keren et al., 2004; Torrey et al., 2016).

The stationary phase stress response is known to trigger the synthesis of $\operatorname{Rel}_{\mathrm{Msm}},-(\mathrm{p}) \mathrm{ppGpp}$ synthetase - that is known as a key player in bacterial stringent response and persistence (Gupta et al., 2016; Prusa et al., 2018). Furthermore, energy-consuming (p)ppGpp synthesis is one of the causes of the cell ATP hydrolysis raising the ADP/ATP ratio that also contributes to persister formation (Krasny and Gourse, 2004; Prossliner et al., 2018; Shan et al., 2017).

Using our constructed M. smegmatis $\mathrm{mc}^{2} 155$ rel $_{\mathrm{Msm}}$ ::lux strain harboring $r e l_{\mathrm{Msm}}$ promoter and $\operatorname{lu} A B$ reporter gene fusion, we showed that induction of $r_{\mathrm{Msm}}$ gene expression occurred during potentiation of the DMNP killing effect (Figure 2C). These data prompted us to speculate that DMNP could target Rel $_{\mathrm{Msm}}$. 

enantiomers with a racemic mixture (Figure 2E). $(+)$-DMNP did not show any noticeable activity against persister cell formation. In contrast, (-)-DMNP proved to be slightly more active than the racemic mixture. Taking into account only a partial advantage of (-)-DMNP over the racemic sample, the further experiments were continued with the racemate. activate synthesis of cell component(s) that are targeted by DMNP. 
Considering literature data (Arai et al., 2014; Incerti-Pradillos et al., 2016; Rodríguez and Ramírez, 2001) and the results presented in the previous section, we proposed that DMNP is likely to affect the Rel ${ }_{\text {Msm }}$ activity, thus making the cells vulnerable to stationary phase stresses.

To validate this assumption, we primarily employed a widely accepted concept that high-

affinity binding of an antimicrobial agent to the abundant specific target, amplified by gene overexpression, reduces the number of the agent's free molecules to the level insufficient to bind the remaining active receptor units, thereby notably decreasing antibacterial effect (Arai et al., 2015; Sato et al., 2010) (Figure 4A). For this, we have primarily used the wild-type M. smegmatis $\mathrm{mc}^{2} 155$ strain transformed by $\mathrm{pMind}-\mathrm{rel}_{\mathrm{Msm}}$ plasmid, whose availability to overexpress $r e l_{\mathrm{Msm}}$ was confirmed by preliminary experiments (Figure S1). We showed that induced overexpression of $r e l_{\mathrm{Msm}}$ in cells exposed to DMNP, in contrast to the cells exposed to clinical antibiotics, produced at least two orders of magnitude higher number of tolerant cells relative to the uninduced counterpart (Figure 4B). Furthermore, a similar inactivation of DMNP was also achieved when $\mathrm{Re}_{\mathrm{Msm}} / \mathrm{DMNP}$ interaction was performed with supplementation of M. smegmatis cultural medium with an relZ overexpression, like that of $r l_{\mathrm{Msm}}$, led to a significant decrease in the antibacterial effect of 
interaction with DMNP (Figure 4A, D). Therefore, both Rel $\mathrm{Msm}_{\text {and }}$ RelZ are of great interest as the

171 proteins promoting persister cell formation that can be viewed as probable targets for DMNP. It

172 should be noted, however, that in addition to the main (p)ppGpp synthetases ( Rel $_{\text {Msm }}$ and RelZ)

173 there are some other (p)ppGpp producers in M. smegmatis cells (Petchiappan et al., 2020). These so

174 far unidentified (p)ppGpp producer(s) may be hypothetically referred to as protein(s), i.e. SASs,

175 that have evolved from the synthetic (SYN) domain integrated in the long multi-domain Rel

176 proteins (Kushwaha et al., 2019). Bacterial cells may carry multiple (p)ppGpp-synthesizing SASs in

177 the same genome that are known to contain similar catalytic domains and are widely spread among different species (Jimmy et al., 2020). These hypothetic producer(s) are responsible for contributing to the total cell pool of (p)ppGpp and persistence, and therefore could be potentially considered as additional target(s) for DMNP.

Indeed, DMNP at a sufficiently high concentration completely suppressed persistence within 12-24 h, and therefore inactivated all (p)ppGpp producers in the parental and the knockout strains, including those so far unidentified (Figure 4H). Alternatively, gradual addition of $\Delta r e l_{\text {Msm }}$ followed by $\Delta r e l_{\mathrm{Msm}} \Delta r e l Z$ knockout mutations to the parental strain exposed to relatively low DMNP concentrations resulted in a proportional decrease in cell potential to form persister cells (parent $>\Delta r e l_{\mathrm{Msm}}>\Delta r e l_{\mathrm{Msm}} \Delta r e l Z$ ) (Figures $\left.4 \mathrm{E}, 4 \mathrm{~F}, 4 \mathrm{G}\right)$. The remaining level of persister formation by knockout strains $\Delta r e l_{\mathrm{Msm}} \Delta r e l Z$ observed at low concentration of DMNP was apparently maintained due to the residual activity of the extant (p)ppGpp synthetases, other than Rel $\mathrm{Msm}_{\text {and RelZ. }}$ Therefore, this suggests that yet unidentified (p)ppGpp producer(s) should be also viewed as DMNP completed persister formation by these time points and hence were less dependent on the (p)ppGpp producers that are inhibited by DMNP. 
transformed with pMind-rel $l_{\mathrm{Msm}}$ returned roughly to that of the parental strain when the plasmid was overexpressed (Figures 4I, 4J). Similar results were observed in both single and double knockout mutants transformed with pMind-relZ (Figures 3L, 3M), thereby supporting the idea that complementation by RelZ rescued the phenotypes of $\Delta r e l_{\mathrm{Msm}}$ strain to a certain extent and therefore both Rel $_{\text {Msm }}$ and RelZ are targeted by DMNP (Figure 4A).

Exponentially growing M. smegmatis cultures, irrespective of whether rel $_{\mathrm{Msm}}$ was overexpressed or not, did not show any measurable differences in the number of cells surviving after exposure to DMNP (Figure S2). However, when the cells entered the stationary phase, a clear increase in the negative effect of DMNP on the cell survival became apparent. This provides further support to our notion that killing effect of DMNP is eventually mediated through stationary phase stresses, whose impacts are controlled by the Rel $\mathrm{l}_{\mathrm{Msm}}$ activity.

Additionally, we found that $\mathrm{pMind}-\mathrm{rel}_{\mathrm{Msm}}$ induction in $M$. smegmatis increased the number of cells tolerant not only to DMNP, but also to Vitamin C (Figure 4K), which was recently shown to also target the Rel ${ }_{\mathrm{Msm}}$ protein (Syal et al., 2017). This agrees with our data on the $\mathrm{rel}_{\mathrm{Msm}}$ overexpression to establish the target for DMNP.

Furthermore, we exposed to DMNP the exponentially growing $M$. smegmatis cells that were preliminary treated by either streptomycin or rifampicin (Figure S3) and found significant suppression of persister formation, down to eradication (Figure S3A). Therefore, the efficiency of clinical antibiotics may be significantly enhanced through banding them together with DMNP to eradicate recalcitrant infections caused by persister forms of Mtb.

\section{DMNP Inhibits (p)ppGpp-Synthesizing Activity}

The results presented so far seem to indicate that the functional activity of $\mathrm{Rel}_{\mathrm{Msm}}$ may be

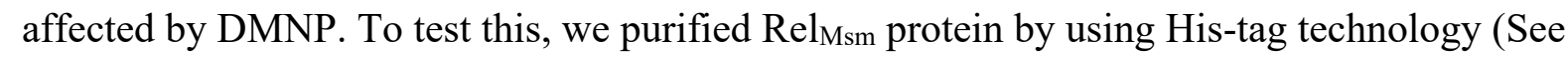

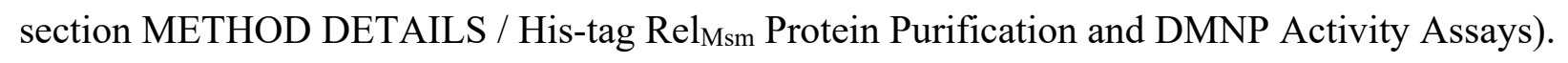


substrate (GTP) and the product ((p)ppGpp), detected by HPLC analysis, in the course of the in vitro reaction (Figure 5; see also Figure S7). The methanol-containing control was used in these measurements. Notably, trace amounts of GDP remained unchanged throughout the course of the reaction, thus excluding unspecific GTP hydrolysis (inset in Figure 5A). The data showed that

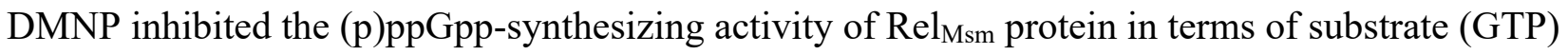
consumption and (p)ppGpp production in a concentration-dependent manner (Figure 5B-C).

Next, for gaining preliminary insight, we performed molecular docking simulations (METHOD DETAILS/Molecular Docking Assay) to pinpoint a plausible location of the DMNP binding site on $\mathrm{Rel}_{\mathrm{Msm}}$ and RelZ proteins surfaces (Figure 6A) and to suggest a potential mechanism of inhibition of their (p)ppGpp-synthesizing activity by DMNP.

For M. smegmatis, crystal structure of Rel protein is not available yet; a PDB search for $M$. tuberculosis (PDB ID 5XNX) identified a structure of the Rel $\mathrm{Mtb}_{\mathrm{tb}}$ protein (Singal et al., 2017) that is closely related to M. smegmatis and share large identities (92\%) in the Rel proteins amino acid sequences. Since the substrate was not present in the protein structure, the calculations of the GTP interaction with amino acids (Y300, Y309, H313, Q327) (Figure 6E) of the active site were based on literature data.

To localize a plausible DMNP binding site, we analyzed surface of the N-terminal domain of the $\mathrm{Rel}_{\mathrm{Mtb}}$ protein in the crystal structure and considered cluster \#1 as a promising candidate due to the highest binding energy $(-7.00 \mathrm{kcal} / \mathrm{mol})$ and the location adjacent to GDP/GTP binding site (Figure 6B). In this arrangement, at least one of the amino acids (HIS177) would interact with both the DMNP inhibitor and the GTP substrate. We also considered TYR306 as an important amino acid due to its proximity to the amino acids of the active site (Y300, Y309, H313, Q327). Therefore, it seems likely that exposure of Rel protein to DMNP would interfere with its binding to GTP, thereby decreasing the (p)ppGpp-synthesizing activity.

Further, it is also reasonable to assume that RelZ, the only SAS identified thus far in $M$. smegmatis, could be targeted by DMNP in a similar fashion because, like other SASs, RelZ is 
analogous to the SYN domain of the multidomain Rel protein (Kushwaha et al., 2019) (Figure 6A,E). M. smegmatis RelZ crystal structure also is not available yet, but there are structural data for several other small alarmone synthetases belonging to different species (Kushwaha et al., 2019). For docking, we chose Staphylococcus aureus RelP (YwaC, SAS2) protein (PDB ID 6EWZ) (Manav et al., 2018) because its crystal structure shows interactions with substrates in the pre-catalytic state. The results of these calculations are more difficult to extrapolate to mycobacteria due to the greater evolutionary distance between the genera Mycobacterium and Staphylococcus, however, these proteins have $29 \%$ identity at their active sites.

Searching for the structural similarity of the DMNP binding pockets specific for $\mathrm{Rel}_{\mathrm{Msm}}$ and RelZ proteins (Figure 6A), the entire surface of RelP (SAS2) protein from Staphylococcus aureus was analyzed with Achilles Blind Docking Server and was compared with the discussed above Rel $l_{\text {Mtb }}$ docking data. The screen revealed a cluster $(-5.40 \mathrm{kcal} / \mathrm{mol})$ (Figure $\left.6 \mathrm{D}\right)$ showing some common features with Rel $_{\mathrm{Mtb}}$ - DMNP binding pocket. Similar to the previous calculations, DMNP could affect the amino acids involved in the GTP interaction with SAS protein (LYS147 and ASN149).

To predict potential interaction of DMNP with both long RSH and SAS proteins in structurally similar binding pockets, we also carried out BLASTp alignment of Rel $\mathrm{M}_{\mathrm{Mtb}}$ and RelP (SAS2) active sites sequences (Figure 6C). The results indicate that amino acids capable of interacting with DMNP are aligned in the adjacent locations (TYR306 from Rel Mtb $_{\text {and }}$ LYS147/ASN149 from RelP) suggesting that in both instances DMNP dockings could occur in similar binding pockets.

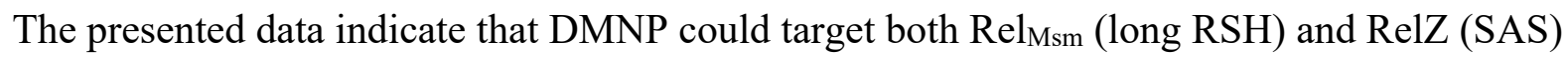
proteins, thereby suppressing persister cell formation through the concentration-dependent inhibition of (p)ppGpp synthetizing activities. Molecular docking simulation data supports the idea that amino acid residues involved in the GTP binding or located near the active sites of both Rel $\mathrm{Msm}_{\mathrm{m}}$ 
272

273

and RelZ could be involved in the interactions of DMNP with these proteins leading to inhibition of their activities.

\section{DMNP Eradicates Biofilms and Affects Cell Sliding Motility}

Sliding motility, biofilm formation and related persister cell formation in mycobacteria referred to as virulence factors contribute to their expansion and resistance to the immune response of a host organism (Dong et al., 2012; Rao et al., 2009).

Based on the reported data (Petchiappan et al., 2020), we hypothesized that DMNP could interfere with the biofilm formation by targeting both (p)ppGpp synthesizing proteins Rel $_{\mathrm{Msm}}$ and RelZ. M. smegmatis forms architecturally complex biofilms (pellicles) at the air/liquid interface of standing cultures that were used as a convenient model for studying the changes in the structural and pellicle mass (dry weight) characteristics of biofilms, depending on the gene structure of $M$. smegmatis cells and their exposure to DMNP. For this purpose, parental strain of M. smegmatis $\mathrm{mc}^{2} 155$ (WT) and two of its derivatives harboring single $\left(\Delta r e l_{\mathrm{Msm}}\right)$ and double $\left(\Delta r e l_{\mathrm{Msm}} \Delta r e l Z\right)$ knockout mutations were used, as well as their pMind-rel $l_{\text {Msm }}$ and pMind-relZ overexpressing transformants (Figure 7A - D; see also Figure S4).

The results showed that single $\left(\Delta r e l_{\mathrm{Msm}}\right)$ and double $\left(\Delta r e l_{\mathrm{Msm}} \Delta r e l Z\right)$ knockout mutants formed atypical biofilms: cells clumped together to form floating islands rather than a single continuous layer across the surface. However, overexpression of $\mathrm{rel}_{\mathrm{Msm}}$ or $\mathrm{relZ}$ in either $\Delta r \mathrm{l}_{\mathrm{Msm}}$ or $\Delta r e l_{\mathrm{Msm}} \Delta r e l Z$ knockout strains of M. smegmatis recovered the biofilm surface, similar to that of the parental strain (Figure 7A).

DMNP inhibited biofilm formation in a concentration-dependent manner (Figure 7B; see also Figure S4), thereby producing the pellicle disassembly in WT, similar to that formed in single $\left(\Delta r e l_{\mathrm{Msm}}\right)$ or double $\left(\Delta r e l_{\mathrm{Msm}} \Delta r e l Z\right)$ knockout strains, even when they were not exposed to DMNP (Figure 7A). 
form pellicles proportionally to the gradual addition of single $\Delta r e l_{\mathrm{Msm}}$ and double $\Delta r e l_{\mathrm{Msm}} \Delta r e l Z$

298

knockout mutations in a concerted manner, similar to that observed for persister cell formation:

$\mathrm{WT}>\Delta r e l_{\mathrm{Msm}}>\Delta r e l_{\mathrm{Msm}} \Delta r e l Z$ (Figure 7B, see also Table S4). The fact that even double knockout mutation $\left(\Delta r e l_{\mathrm{Msm}} \Delta r e l Z\right)$ by itself still fails to completely suppress the formation of biofilms, akin to persister cell formation, supports the notion that M. smegmatis cells contain some other (p)ppGpp producer(s), yet unidentified, in agreement with the report by Petchiappan et al (Petchiappan et al., 2020). Furthermore, the activity of these producer(s) can be completely suppressed by sufficiently high concentration of DMNP (Figure 7B; see also Figure S4) and therefore, as already discussed, they can be considered as likely additional targets(s) for DMNP.

Alternatively, overexpression of $\mathrm{rel}_{\mathrm{Msm}}$, or to a lesser extent $\mathrm{relZ}$, has partially rescued biofilm formation by either shifting the minimal biofilm destructive concentrations (MBDC, $\mu \mathrm{g} / \mathrm{mL})$ to higher values in WT exposed to DMNP or increasing p.m. values in WT and knockout strains (Figure 7B, see also Figure S4 and Tables S4, S5). However, planktonic growth was still detectable in the range from minimal biofilm destructive concentrations to minimal bactericidal concentrations (MBC) (Figure 7C; see also Table S6). Both MBDC and MBEC (minimal biofilm eradication concentration) actually have the same nature. The latter is commonly used to characterize biofilm eradication activity of antibacterials through $\mathrm{MBC} / \mathrm{MBEC}$ ratios that for the biofilm-eradicating agents typically have values in the range of 1 to 3 (Garrison and Huigens, 2017). Considering the high levels of the MBC/MBDC ratios observed here (about 2 to 3), DMNP can be viewed as a biofilm-eradicating agent (Figure 7C). Furthermore, this DMNP property was dependent on the rel $_{\mathrm{Msm}}$ and relZ genes: the MBC/MBDC ratio increased from 2.25 for WT to 3.25 for knockout strains $\left(\Delta r e l_{\mathrm{Msm}}\right.$ and $\left.\Delta r e l_{\mathrm{Msm}} \Delta r e l Z\right)$ and returned to the original values in response to $r e l_{\mathrm{Msm}^{-}}$ overexpression (Figure 7C). We compared the results of the MBC/MBDC measurements with those for the MBC/MBEC ratios for WT that were conducted with the MBEC ${ }^{\text {TM }}$ Biofilm Inoculator (Innovotech, Canada) for DMNP and the conventional antibiotics (Table S3). Although DMNP 
exhibited lower MBC/MBEC value (1.25) for WT strain as compared to MBC/MBDC (2.25), it still falls into the category of biofilm-eradicating agents, unlike the conventional antibiotics we tested (Garrison and Huigens, 2017).

These results were validated by experiments showing that DMNP could selectively inhibit biofilm formation in a concentration-dependent manner over a range of concentrations $(0.07-0.57$ $\mathrm{mM}$ ) that had no discernible inhibitory effect on the growing planktonic cells (Figure 7D).

However, unlike DMNP, all of the conventional antibiotics tested in this work, as exemplified by rifampicin (Figure 7E), were equally effective against both planktonic and biofilm M. smegmatis cells. This confirms our findings that DMNP preferentially inhibits biofilm formation versus planktonic growth and therefore is consistent with the idea that it targets Rel $\mathrm{Msm}_{\mathrm{Ms}}$ and RelZ proteins. Such alterations form "macroscopic surface phenotype" displaying a limited cell sliding motility and rough colony morphology (Gupta et al., 2016; Gupta et al., 2015) .

Measurement of Zeta potential in M. smegmatis cells exposed to DMNP displayed a concentration-dependent reduction in the value of the cell surface negative charge (Figure S5A). Together with the increase in the cell wall hydrophobicity, this indicates that DMNP, akin to $\Delta r e l_{\text {Msm }}$ mutation, is able to affect the cell surface properties. Furthermore, DMNP contributed to the formation of rough colony morphology in both WT and knockout derivatives (Figure 7F), thereby emulating macroscopic cell surface phenotype that was observed specifically for $\Delta r e l_{\text {Msm }} M$. smegmatis cells (Gupta et al., 2015). In contrast, conventional antibiotics do not produce similar alterations (Figure S6).

We have now demonstrated that DMNP reduced the sliding motility of M. smegmatis cells owing to its ability to impair cell surface (Figure $7 \mathrm{G})$. The area of sliding colonies $\left(\mathrm{mm}^{2}\right)$ (See section METHOD DETAILS/ Cell Sliding Motility) decreased while their specific optical density (SOD) proportionally increased over a range of subinhibitory DMNP concentrations $(0.02-0.05$ $\mathrm{mM}$ ) as compared to the control (Figure S5B). The data indicate that the limitation of sliding motility at these concentrations occurred with no discernible inhibition of cell growth as suggested 
by an increase in SOD that was reversely proportional to the area of sliding colony. However, a

further increase in DMNP concentration led to decrease in SOD, thus exhibiting partial inhibition of cell growth occurring in addition to inhibition of sliding motility (Figure S5B).

The results show that DMNP, by interfering with functions of the $\operatorname{Rel}_{\mathrm{Msm}}$, RelZ and presumably of some other unidentified (p)ppGpp producer(s), inhibits them in a manner similar to phenotype of $\Delta r e l_{\mathrm{Msm}}$ or/and $\Delta r e l Z$ knockout mutations. This adds to the body of evidence that both Rel $_{\text {Msm }}$ and RelZ could be indeed targeted by DMNP.

\section{Discussion}

Bacterial persistence coupled with biofilm formation are associated with the failure of antibiotic treatment of TB that poses a unique challenge for developing new therapies. Preliminary screening of a variety of synthetic derivatives of marine diterpene erogorgiaene identified 4-(4,7DiMethyl-1,2,3,4- tetrahydroNaphthalene-1yl)Pentanoic acid (DMNP) as the most active antipersister lead compound (Figure 2B), which was used in this study. Presently, one of the most important regulators of bacterial persistence involved in cell adaptation to stationary-phase stresses is a hyperphosphorylated guanosine analog (p)ppGpp (Brown et al., 2016). In mycobacteria, (p)ppGpp is synthesized and is broken down by the dualfunction enzyme Rel that is referred to as RSH (RelA/SpoT homolog) proteins (Atkinson et al., 2011; Gupta et al., 2016).

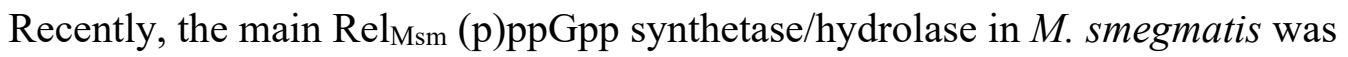
complimented by RelZ protein that is referred to as short alarmone synthetases (SASs). RelZ, in addition to ability of maintaining basal (p)ppGpp level, contains a RNase HII domain that is implicated in R-loop induced stress response (Petchiappan et al., 2020). Furthermore, Petchiappan et al found that the $\Delta r e l_{\mathrm{Msm}} \Delta r e l Z$ M. smegmatis strain is still capable of synthesizing (p)ppGpp, thereby indicating the presence of some other (p)ppGpp producer(s) in this organism (Petchiappan et al., 2020). Although they have not been so far identified and characterized in M. smegmatis, these 
(p)ppGpp producer(s) may be putatively referred to as SAS(s) because a large number of bacterial species are known to carry multiple (p)ppGpp-synthesising SASs in the same genome (Jimmy et al., 2020). All currently known short alarmone synthetases have evolved from the synthetic (SYN) domain integrated in the long multi-domain Rel proteins reflecting their similarity to its single catalytic domain (Kushwaha et al., 2019).

The literature data and our initial results indicated that, in addition to Rel $_{\mathrm{Msm}}$ and RelZ, some other, so far unidentified (p)ppGpp producer(s) are capable to contribute to the formation of persister cells and can be targeted by DMNP. Recently, formation of biofilms containing persister cells responsible for the recalcitrance of mycobacterial infections (Sharma et al., 2014) was also shown to be a (p)ppGpp-dependent process (Pacios et al., 2020). Furthermore $\Delta r{ }_{\text {Msm }}$ and $\Delta r e l_{\mathrm{Msm}} \Delta r e l Z$, single and double gene knockout mutants, are defective in biofilm formation and have altered cell surface properties (Petchiappan et al., 2020). Therefore, our hypothesis that (p)ppGpp synthetases (Rel, SASs) represent the multiple targets for DMNP seems to be also relevant for the biofilm formation.

We verified this hypothesis by using two reciprocal experimental approaches, $\Delta r \mathrm{rel}_{\mathrm{Msm}}$ and $\Delta r e l Z$ gene knockout mutations versus rel $_{\mathrm{Msm}}$ and $\mathrm{relZ}$ overexpression technique. Accordingly, at sufficiently high concentration, DMNP exhibited complete suppression of persistence and biofilm formation mediated through the inhibition of all (p)ppGpp producers functioning in the parental strain, including Rel $_{\mathrm{Msm}}$, RelZ and so far unidentified species (Figure 4H; Figure 7; see also Figure S4). At the same time, sequential addition of $\Delta r e l_{\mathrm{Msm}}$ and $\Delta r e l_{\mathrm{Msm}} \Delta r e l Z$ knockout mutations to the cells that were then exposed to DMNP in the range of lower concentrations resulted in a proportional decrease in the cell potential to form persister cells and biofilms (parent $>\Delta r e l_{\mathrm{Msm}}>$ $\Delta r e l_{\mathrm{Msm}} \Delta r e l Z$ ). It should be noted, however, that in this case the remaining level of persister and biofilm formation was maintained at the expense of the residual activity of the extant (p)ppGpp

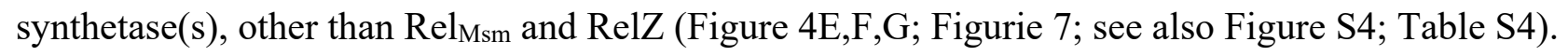


400

401

402

403

404

405

406

407

strains transformed with either $\mathrm{pMind}-\mathrm{rel}_{\mathrm{Msm}}$ or pMind-relZ plasmids reverted formation of persisters and biofilms close to their natural levels (Figure 4 I,J,L,M; Figure 7; see also Figure S4; Table S5). Similar data were obtained when the protocol was reproduced with Vitamin C (Figure 4K), another agent capable to competitively inhibit (p)ppGpp-synthesizing activity of Rel $\mathrm{Msm}_{\text {(Syal }}$ et al., 2017).

These data indicate that both $\mathrm{Rel}_{\mathrm{Msm}}$ and RelZ can be viewed as the targets for DMNP, which are able to at least partially complement each other in the formation of persister cells and biofilms Therefore, both approaches realized in this work support our hypothesis that DMNP can target not

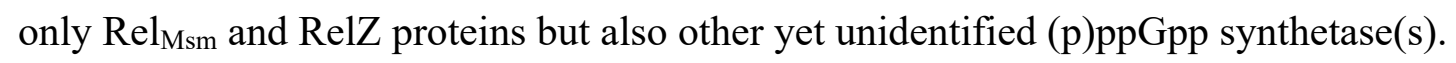

Finally, we purified recombinant Rel $_{\text {Msm }}$ protein and measured its (p)ppGpp-synthesizing activity in the presence of DMNP at different concentrations with reference to the control with no antibiotic (Figure 5). The data revealed that the activity of Rel $_{\mathrm{Msm}}$ is inhibited by DMNP in a concentration-dependent manner, thus supporting the conclusion that $\mathrm{Re}_{\mathrm{Msm}}$ is indeed targeted by DMNP.

The experimental findings and preliminary computational data obtained from molecular docking modeling (Figure 6) strongly suggest that DMNP can bind to the structurally similar active sites in the proteins, collectively referred to as Rel and SAS, through a common mechanism, thereby inhibiting their (p)ppGpp-synthesizing activities.

We showed here that DMNP used in combination with either streptomycin or rifampicin significantly enhanced their killing effect on M. smegmatis cells by interferring with persister cell formation (Figure S3). Furthermore, DMNP, unlike the conventional antibiotics, can be viewed as a biofilm-eradicating agent characterized by a favorable MBC/MBDC ratio (about 2 to 3) (Figure 7C) or MBC/MBEC ratio of 1.25 (Table S3) (Garrison and Huigens, 2017). Therefore, antipersistent substances elaborated on the basis of DMNP could be used potentially in combination with conventional antibiotics to eradicate chronic infections including tuberculosis. 
426 contribute to a body of evidence that the mechanism of the antimycobacterial effect of DMNP

427 involves its binding to (p)ppGpp synthetases (primarily $\mathrm{Rel}_{\mathrm{Msm}}$ and RelZ proteins) leading to

428 inhibition of the processes relevant to persistence and biofilm formation. Therefore, DMNP may

429 serve as a promising lead compound for developing antitubercular therapies relying on suppression

430 of persister cell formation and thus effective against chronic and recalcitrant tuberculosis infections.

431 
433

434

435

436

437

438

439

440

441

442

443

444

Synthetic analogue of marine diterpene erogorgiaene, 4-(4,7- DiMethyl-1,2,3,4-

tetrahydroNaphthalene-1-yl)Pentanoic acid (DMNP), emerged as a promising lead compound targeting mycobacterial persister cell formation. To identify the DMNP target(s), fast growing Mycobacterium smegmatis was used as a model organism that shares phenotypic and genetic similarities with Mtb. Hyperphosphorylated guanosine analogue (p)ppGpp, the product of Rel $\mathrm{Msm}_{\mathrm{m}}$ and RelZ alarmone synthetases is known to be one of the most important regulators of bacterial persistence. Cells treated with DMNP exhibited a phenotype similar to that caused by the loss of functions by alarmone synthetases, including persistence and biofilm formation. In vitro experiments demonstrated that (p)ppGpp-synthesizing activity of purified recombinant Rel $_{\mathrm{Msm}}$ protein is inhibited by DMNP in a concentration-dependent manner. Finally, molecular docking simulations suggest that DMNP could be binding to Rel $\mathrm{Msm}_{\mathrm{m}}$ and RelZ proteins in close proximity to their highly similar GTP binding sites, thereby inhibiting their (p)ppGpp-synthesizing activity. Therefore, the data obtained might be used for developing antitubercular drugs to eradicate recalcitrant infections.

\section{Acknowledgements}

We thank A. Goncharenko for comments and discussion and M. Shumkov for technical assistance The authors thank the Russian Science Foundation for Grant No. 18-73-10156

\section{Author Contributions}

A.E.R., A.G.T. and A.V.M. initiated the study and directed the project. A.E.R., V.Yu.V., S.A.Sh. and A.V.M. carried out the stereoselective synthesis and characterized the diterpenoids used in this study. N.M.K. evaluated killing potency of DMNP and persister cell formation of M. smegmatis throughout the experimental work and assessed rel $_{\mathrm{Msm}}$ and $r e l Z$ gene expression. R.Yu.S. prepared 
457 all genetic constructs used in this work, including pMind-rel $l_{\text {Msm }}$ and pMind-relZ overexpressing 458 plasmid, $r e l_{\mathrm{Msm}} .: l u x A B$ gene fusion, $r e l_{M s m}$ and $r e l Z$ knockout strains and pET23b-rel $l_{\mathrm{Msm}}$ (His) 459 plasmid for His-Tag protein purification, and performed molecular docking simulation to predict 460 the probable binding mode between DMNP and Rel ${ }_{\text {Msm }}$ and RelZ proteins. Biofilm eradicating 461 assays, antibiotic susceptibility, as well as Zeta potential and hydrophobicity assays were performed 462 by L.Yu.N. Rel $\mathrm{Msm}_{\text {sm }}$ protein His-Tag purification and in vitro (p)ppGpp synthesis assay, as well as 463 HPLC analysis of nucleotides were carried out by A.V.A. Effect of DMNP on M. smegmatis 464 pellicle formation, sliding motility and colony morphology assays, were performed by I.V.T. 465 A.G.T. composed the paper with input from A.V.M. and A.E.R. All authors read and approved the 466 final manuscript. 
Figure 1. Stereoselective synthesis of (-)-DMNP 2

\section{Figure 2. Negative Effect of DMNP on Cell Survival Is Potentiated during Transition to} Stationary Phase

(A) Experimental design (See METHOD DETAILS /Cell Viability and Persister Cell Number; Overexpression Assays).

(B) Structures of (-)-DMNP (1) and (+)-DMNP (2).

(C) Dynamics of cells exposed to conventional antibiotics versus those treated by racemic DMNP in relation to the expression level of rel $_{\mathrm{Msm}}$.

Culturable cells - the control cells untreated with antibiotics or DMNP; bioluminescence - the expression level of rel $_{\mathrm{Msm}}$; antibiotics were added to final concentrations (mM): 1.06 DMNP, 1.17 rifampicin (Rif), 0.094 tetracycline (Tetr), 0.0034 streptomycin (Str)

(D) Decline in cell energy state as an indicator of persister cell formation.

The EC (adenylate energy charge) and ADP/ATP values are represented vs the growth curve.

(E) Comparative dynamics of tolerant cells in M. smegmatis $\mathrm{mc}^{2} 155$ batch culture survived after exposure to $( \pm)$-DMNP, $(-)$-DMNP- and (+)-DMNP, all in concentration of $1.06 \mathrm{mM}$. Experimental data are presented as mean values of at least three independent experiments, and the error bars represent the standard error of the mean of the independent measurements.

\section{Figure 3. DMNP Cell Killing Activity, Unlike Conventional Antibiotics, Is Maximal in} Standing Cultures

(A) Experimental design. For the cultivation conditions, see METHOD DETAILS /Cell Viability and Persister Cell Number.

(B, C) Rifampicin $1.17 \mathrm{mM}$.

(D, E) Tetracycline $0.094 \mathrm{mM}$.

(F, G) Streptomycine $0.0034 \mathrm{mM}$.

(H, I) DMNP $1.06 \mathrm{mM}$.

Experimental data are presented as mean values of at least three independent experiments, and the error bars represent the standard error of the mean of the independent measurements.

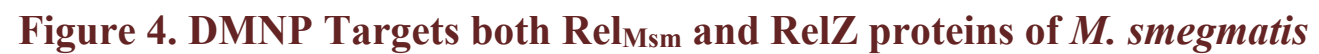

(A) Experimental design. For details see METHOD DETAILS / Cell Viability and Persister Cell Number.

(B) Overexpression of $r e l_{\mathrm{Msm}}$ in $M$. smegmatis cells results in the decrease in DMNP antibacterial effect unlike that of conventional antibiotics. Following concentrations of antibiotics were used (mM): 0.96 DMNP, 0.0034 streptomycin, 0.094 tetracycline, 1.17 rifampicin. For details see METHOD DETAILS / Overexpression Assays.

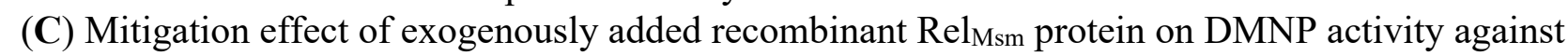
M. smegmatis. For details see METHOD DETAILS / His-tag Rel $\mathrm{l}_{\text {Msm }}$ Protein Purification and DMNP Activity Assays.

(D) Overexpression of relZ in M. smegmatis cells results in the decrease in DMNP antibacterial effect. For details see METHOD DETAILS / Overexpression Assays.

$(\mathbf{E}, \mathbf{F}, \mathbf{G}, \mathbf{H})$ Concentration-dependent effect of DMNP against $M$. smegmatis is potentiated in parallel with addition of chromosome knockout mutations in $\mathrm{rel}_{\mathrm{Msm}}$ and $\mathrm{relZ}$ alarmone synthetase genes.

(I, J) Overexpression of $r_{\text {Msm }}$ in M. smegmatis $\Delta r e l_{\text {Msm }}$ pMind-rel $l_{\text {Msm }}$ or $\Delta r e l_{\mathrm{Msm}} \Delta r e l Z$ pMindrel $_{\text {Msm }}$ strains mitigates DMNP effect. 
(K) Growth phase-dependent effect of rel $_{\mathrm{Msm}}$ overexpression on survival of $M$. smegmatis $\mathrm{mc}^{2} 155$

The strain and growth conditions were used as in METHOD DETAILS/ Overexpression Assays, except the cells were taken from both induced and uninduced batch cultures at the following time points: $0-4 \mathrm{~h}$ (exponential phase), $6 \mathrm{~h}$ (the onset of transition to stationary phase), $24 \mathrm{~h}$ (early stationary phase), and $48 \mathrm{~h}$ (mid-stationary phase ). Vitamin $\mathrm{C}$ was added to the cells in the volume of $20 \mu \mathrm{L}$ to the final $75 \mathrm{mM}$ concentration.

(L, M) Overexpression of relZ in M. smegmatis $\Delta$ rel $_{\mathrm{Msm}} \mathrm{pMind}-r e l \mathrm{Z}$ or $\Delta$ rel $_{\mathrm{Msm}} \Delta r e l Z \mathrm{pMind}-\mathrm{relZ}$ strains mitigates DMNP effect.

Data are presented as mean \pm SEM values of at least three independent experiments.

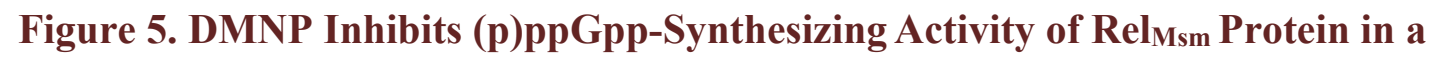 Concentration-Dependent Manner}

(A) Rel $_{\text {Msm }}$ activity is quantified by decrease in the concentration of the substrate (GTP). Data are presented as mean \pm SEM values of at least three independent experiments each performed in triplicate. Asterisks indicate significant differences $(t$-test, $p<0.05)$ compared to the control with added methanol (met); cross indicates significant difference compared to the control with no added methanol (contr).

The box in the top right corner shows HPLC analysis of guanosine nucleotides in the samples taken from the enzymatic system at different time points. The data are shown as overlapping HPLC traces taken at the specified time points (UV detection at $254 \mathrm{nM}$, See also Figure S7).

(B) Dynamics of the substrate (GTP) concentration in the process of the (p)ppGpp synthesis catalyzed by purified $\mathrm{Re}_{\mathrm{Msm}}$ protein depending on the DMNP concentration.

(C) Dynamics of the product ((p)ppGpp) concentration synthesized by purified Rel Msm $_{\text {protein }}$ depending on the DMNP concentration.

For details see METHOD DETAILS / His-tag Rel $\mathrm{Msm}_{\mathrm{Ms}}$ Protein Purification and DMNP Activity Assays

\section{Figure 6. Molecular Docking Modelling of DMNP Targeting Long RSH and SAS (p)ppGpp} Synthetases

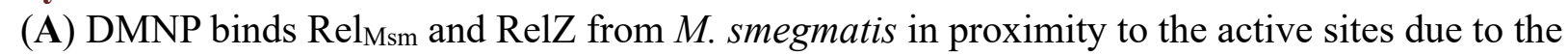
structural similarities in synthetase domains (Scheme). HD - hydrolase domain; SYN - synthetase domain; REG - regulatory lobe, which includes TGS, AH, ZFD and ACT domains; RHII - RNase HII domain. Images were computationally generated and may not be consistent with actual Rel $\mathrm{Msm}_{\mathrm{Ms}}$ and RelZ proteins structures, which are not available at the time (See METHOD DETAILS/ Molecular Docking Assay).

(B) Molecular docking simulation shows a probable binding mode between DMNP and $M$. tuberculosis $\mathrm{Rel}_{\mathrm{Mtb}}$ protein. Amino acids (AAs) interacting with DMNP only are colored in orange, AAs interacting with GTP only are colored in purple, AAs interacting with both GTP and DMNP are colored in red. HIS177 can interact with both DMNP (inhibitor) and GTP (substrate). TYR306 might be crucial to DMNP activity due to a close location to the AAs of the active site. Both Rel $\mathrm{Mtb}^{-}$ DMNP and Rel $1_{\mathrm{Mtb}}$-GTP interactions are calculated using molecular docking.

(C) BLASTp alignment of Rel $\mathrm{Mtb}_{\mathrm{tb}}$ and SAS2 amino acid sequences shows that amino acids binding with DMNP close to the active site belong to similar binding pockets.

(D) Molecular docking simulation predicts a probable binding mode between DMNP and S. aureus SAS2 protein. AAs are colored as in (B). LYS147 and ASN149 can interact with both DMNP (inhibitor) and GTP (substrate). SAS2-DMNP interactions were calculated using docking, while SAS2-GTP interactions were shown in the SAS2 crystal structure.

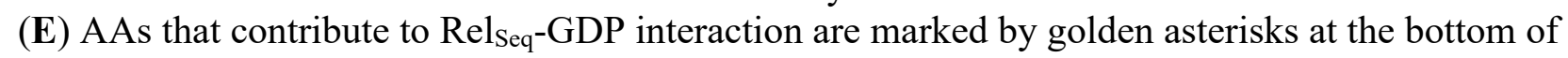
the alignment of Rel proteins from different species to identify Rel ${ }_{\text {Mtb }}$ residues contributing to the interaction with the substrate. 
571 Figure 7. Effect of DMNP on Biofilm Formation and Cell Surface Phenotype of M. smegmatis

$572 \mathrm{mc}^{2} 155$

573 For detail see in METHOD DETAILS / Antibiotic Susceptibility and Biofilm-Eradication Assays.

574 (A) Biofilm disassembly produced by DMNP or single $\left(\Delta \mathrm{rel}_{\mathrm{Msm}}\right)$ and double $\left(\Delta r e \mathrm{Msm}_{\mathrm{Ms}} \Delta \mathrm{relZ}\right)$

575 knockout mutations is rescued by overexpression of either $\mathrm{rel}_{\mathrm{Msm}}$ or $\mathrm{relZ}$ genes (Photo).

576 (B) Concentration-dependent inhibitory effect of DMNP on biofilm formation in WT strain is 577 potentiated by single $\left(\Delta \mathrm{rel}_{\mathrm{Msm}}\right)$ and double $\left(\Delta r e l_{\mathrm{Msm}} \Delta \mathrm{relZ}\right)$ knockout mutations. Enhancement of

578 DMNP inhibitory effect on biofilm formation produced by $\Delta \mathrm{rel}_{\mathrm{Msm}}$ mutation is rescued by $\mathrm{rel}_{\mathrm{Msm}^{-}}$ 579 overexpression (hatched area). For detail see Tables S3, S4. The area of difference in p.m. values

580 between of $\Delta r e l_{\mathrm{Msm}}$ and $\Delta r e l_{\mathrm{Msm}} \Delta r e l Z$ knockout strains is marked in yellow, whereas that between

581 WT and rel $_{\mathrm{Msm}}$-overexpression area is marked in blue.

582 (C) Biofilm eradication activity of DMNP in terms of MBDC and MBC/MBDC interrelations is

583 dependent on rel $_{\text {Msm }}$ and relZ genes. For detail see Tables S5.

584 (D) Subinhibitory DMNP concentrations specifically inhibit biofilm formation, not planktonic 585 growth.

586 (E) Rifampicin, in contrast to DMNP, has nearly equal inhibitory effect against both biofilm 587 formation and planktonic growth.

588 (F) DMNP effect on colony surface morphology of the parent M. smegmatis $\mathrm{mc}^{2} 155$ strain and its 589 knockout derivatives (Photos).

590 (G) DMNP effect on sliding motility (Photos). For detail see Figure S6 and METHOD DETAILS / 591 Sliding Motility.

592 Data are presented as mean \pm SEM values of at least three independent experiments. 


\section{Resource Availability}

596 KEY RESOURCES TABLE

\begin{tabular}{|c|c|c|}
\hline REAGENT or RESOURCE & SOURCE & IDENTIFIER \\
\hline \multicolumn{3}{|l|}{ Antibodies } \\
\hline & & \\
\hline & & \\
\hline & & \\
\hline \multicolumn{3}{|l|}{ Bacterial and Virus Strains } \\
\hline Escherichia coli $\mathrm{BMH}$ & Promega & K12 BMH 71-18 \\
\hline E. coli BL21(DE3) & Novagen & Cat\#69450 \\
\hline E. coli RO91 & $\begin{array}{l}\text { Dr.R. Hengge- } \\
\text { Aronis (Institut für } \\
\text { Biologie, } \\
\text { Mikrobiologie, Freie } \\
\text { Universität Berlin) } \\
\text { (Lange and Hengge- } \\
\text { Aronis, 1994) }\end{array}$ & $\mathrm{N} / \mathrm{A}$ \\
\hline $\begin{array}{l}\text { Mycolicibacterium smegmatis (basonym } \\
\text { Mycobacterium smegmatis) } \mathrm{mc}^{2} 155\end{array}$ & $\begin{array}{l}\text { A.N. Bach Institute } \\
\text { of Biochemistry }\end{array}$ & NC_008596 \\
\hline \multicolumn{3}{|l|}{$\begin{array}{l}\text { Other } E \text {. coli and } M \text {. smegmatis strains constructed } \\
\text { and used in this study, see Table S1 }\end{array}$} \\
\hline \multicolumn{3}{|l|}{ Biological Samples } \\
\hline \multicolumn{3}{|l|}{ Chemicals, Peptides, and Recombinant Proteins } \\
\hline $\begin{array}{l}\text { DMNP (4-(4,7-DiMethyl-1,2,3,4- } \\
\text { tetrahydroNaphthalene-1-yl)Pentanoic acid) }\end{array}$ & This paper & $\mathrm{N} / \mathrm{A}$ \\
\hline$N, N$-Diisopropylethylamine & Sigma-Aldrich (USA) & Cat\#387649 \\
\hline Potassium hydride & Sigma-Aldrich (USA) & Cat\#215813 \\
\hline 2,4,6-Tri-tert-butylphenol & $\begin{array}{l}\text { abcr GmbH } \\
\text { (Germany) }\end{array}$ & Cat\#AB142941 \\
\hline 18-Crown-6 & Sigma-Aldrich (USA) & Cat\#186651 \\
\hline Trimethyl phosphonoacetate & AlfaAesar (UK) & Cat\#A13301 \\
\hline Methanesulfonic acid & $\begin{array}{l}\text { abcr GmbH } \\
\text { (Germany) }\end{array}$ & Cat\#AB110742 \\
\hline Palladium on carbon & Sigma-Aldrich(USA) & Cat\#205699 \\
\hline $\mathrm{Rh}_{2}(\mathrm{R}-\mathrm{DOSP})_{4}$ & $\begin{array}{l}\text { Strem Chemicals, } \\
\text { Inc (USA) }\end{array}$ & Cat\#45-2100 \\
\hline His-tagged M.smegmatis Rel ${ }_{\text {Msm }}$ & This paper & $\mathrm{N} / \mathrm{A}$ \\
\hline $\begin{array}{l}\text { Restriction enzymes, DNA polymerases, T4 DNA } \\
\text { Ligase, CIAP }\end{array}$ & $\begin{array}{l}\text { Thermo Fisher } \\
\text { Scientific (USA) }\end{array}$ & $\mathrm{N} / \mathrm{A}$ \\
\hline Kanamycin Sulfate & $\begin{array}{l}\text { PanReac } \\
\text { AppliChem } \\
\text { (Germany) }\end{array}$ & Cat\#A1493 \\
\hline
\end{tabular}




\begin{tabular}{|c|c|c|}
\hline Ampicillin Sodium Salt & $\begin{array}{l}\text { PanReac } \\
\text { AppliChem } \\
\text { (Germany) }\end{array}$ & Cat\#A0839 \\
\hline Hygromycin B Gold & InvivoGen (USA) & Cat\#31282-04-9 \\
\hline Tetracycline hydrochloride & Sigma (USA) & Cat\#T3383 \\
\hline Streptomycin sulfate & $\begin{array}{l}\text { PanReac } \\
\text { AppliChem } \\
\text { (Germany) }\end{array}$ & Cat\#A1852 \\
\hline Rifampicin & $\begin{array}{l}\text { PanReac } \\
\text { AppliChem } \\
\text { (Germany) }\end{array}$ & Cat\#A2220 \\
\hline Isoniazid & Sigma (USA) & Cat\#I3377 \\
\hline Ethambutol dihydrochloride & Sigma (USA) & Cat\#E4630 \\
\hline Guanosine-3',5'-bisdiphosphate & $\begin{array}{l}\text { Jena Bioscience } \\
\text { (Germany) }\end{array}$ & Cat\#NU884S \\
\hline \multicolumn{3}{|l|}{ Critical Commercial Assays } \\
\hline & & \\
\hline & & \\
\hline \multicolumn{3}{|l|}{ Deposited Data } \\
\hline & & \\
\hline & & \\
\hline & & \\
\hline \multicolumn{3}{|l|}{ Experimental Models: Cell Lines } \\
\hline & & \\
\hline & & \\
\hline & & \\
\hline \multicolumn{3}{|l|}{ Experimental Models: Organisms/Strains } \\
\hline & & \\
\hline & & \\
\hline & & \\
\hline \multicolumn{3}{|l|}{ Oligonucleotides } \\
\hline Primers used in this study, see Table S1 for details & This paper & $\mathrm{N} / \mathrm{A}$ \\
\hline & & \\
\hline & & \\
\hline \multicolumn{3}{|l|}{ Recombinant DNA } \\
\hline Plasmid: pET23b & Novagen & Cat\#69746 \\
\hline Plasmid: pTZ57R & $\begin{array}{l}\text { Thermo Fisher } \\
\text { Scientific }\end{array}$ & Cat\#K1214 \\
\hline Plasmid: pMind & $\begin{array}{l}\text { Addgene (Blokpoel } \\
\text { et al., 2005) }\end{array}$ & $\begin{array}{l}\text { RRID:Addgene_24 } \\
730\end{array}$ \\
\hline
\end{tabular}




\begin{tabular}{|c|c|c|}
\hline Plasmid: pKW08-Lx-Int & $\begin{array}{l}\text { Addgene (Williams } \\
\text { et al., 2010) }\end{array}$ & $\begin{array}{l}\text { RRID:Addgene_25 } \\
015\end{array}$ \\
\hline Plasmid: p2NIL & $\begin{array}{l}\text { Addgene (Parish } \\
\text { and Stoker, 2000) }\end{array}$ & $\begin{array}{l}\text { RRID:Addgene_20 } \\
188\end{array}$ \\
\hline Plasmid: pGOAL19 & $\begin{array}{l}\text { Addgene (Parish } \\
\text { and Stoker, 2000) }\end{array}$ & $\begin{array}{l}\text { RRID:Addgene_20 } \\
190\end{array}$ \\
\hline Plasmid: pET23b-re/Msm & This paper & $\begin{array}{l}\text { RRID:Addgene_16 } \\
6043\end{array}$ \\
\hline Plasmid: pMind-re/Msm & This paper & $\begin{array}{l}\text { RRID:Addgene_16 } \\
6044\end{array}$ \\
\hline Plasmid: pMind-relZ & This paper & $\begin{array}{l}\text { RRID:Addgene_16 } \\
6045\end{array}$ \\
\hline Plasmid: pKW08-rel-Lx-Int & This paper & $\begin{array}{l}\text { RRID:Addgene_16 } \\
6046\end{array}$ \\
\hline Plasmid: p2NIL-re/Msm & This paper & $\begin{array}{l}\text { RRID:Addgene_16 } \\
6047\end{array}$ \\
\hline Plasmid: p2NIL-relZ & This paper & $\begin{array}{l}\text { RRID:Addgene_16 } \\
6048\end{array}$ \\
\hline \multicolumn{3}{|l|}{$\begin{array}{l}\text { Additional information about plasmids is provided in } \\
\text { Table S1. }\end{array}$} \\
\hline \multicolumn{3}{|l|}{ Software and Algorithms } \\
\hline AutoDock Vina v1.1.2 & $\begin{array}{l}\text { (Trott and Olson, } \\
2010)\end{array}$ & $\begin{array}{l}\text { RRID:SCR_01195 } \\
8\end{array}$ \\
\hline ClustalX v2.1 & (Larkin et al., 2007) & $\begin{array}{l}\text { RRID:SCR_01705 } \\
5\end{array}$ \\
\hline Achilles Blind Docking Sever & $\begin{array}{l}\text { (Sanchez-Linares et } \\
\text { al., 2012) }\end{array}$ & N/A \\
\hline BLASTp v2.10.0 & $\begin{array}{l}\text { (Camacho et al., } \\
\text { 2009) }\end{array}$ & $\begin{array}{l}\text { RRID:SCR_00101 } \\
0\end{array}$ \\
\hline PyMOL v2.3.0 & Schrodinger, Inc. & $\begin{array}{l}\text { RRID:SCR_00030 } \\
5\end{array}$ \\
\hline GalaxyTBM & (Ko et al., 2012) & N/A \\
\hline Protein-Ligand Interaction Profiler v2.1.3 & $\begin{array}{l}\text { (Salentin et al., } \\
\text { 2015) }\end{array}$ & GitHub c8d4c8d \\
\hline Statistica for Windows 5.0 & StatSoft, Inc., 1995 & $\begin{array}{l}\text { RRID:SCR_01421 } \\
3\end{array}$ \\
\hline \multicolumn{3}{|l|}{ Other } \\
\hline & & \\
\hline & & \\
\hline & & \\
\hline
\end{tabular}

\section{$598 \quad$ Lead Contact}

599 Further information and requests for responding to material, resources and reagents should be 600 directed to and will be fulfilled by the Lead Contact, Andrei V. Malkov (a.malkov@,lboro.ac.uk).

\section{Materials Availability}

602 All unique reagents generated in this study are available from the Lead Contact. The availability of

603 DMNP may be limited to a small batch and might require resynthesis. Plasmid generated in this

604 study will be deposited to Addgene (https://www.addgene.org/). 
606 The published article includes all biological data generated during this study. This study did not 607 generate code.

\section{Experimental Model and Subject Details}

\section{Growth Conditions}

M. smegmatis $\mathrm{mc}^{2} 155$ cells were grown overnight in a glass tube with $5 \mathrm{~mL}$ of Middlebrook $7 \mathrm{H} 9$ broth (Difco) containing $0.5 \%$ glycerol, $0.05 \%$ Tween 80 and $50 \mu \mathrm{g} / \mathrm{mL}$ ampicillin with agitation on shaker GFL1092 (GFL, Germany) $\left(200 \mathrm{rpm}, 37^{\circ} \mathrm{C}\right)$. The grown cells were then diluted 1:50 with fresh medium and $50 \mathrm{~mL}$ of culture were further cultivated in $250 \mathrm{~mL}$ Erlenmeyer flasks under the above conditions with the registration of growth by optical density $\left(\mathrm{A}_{600}\right)$ recorded by UV-1650PC spectrophotometer (Shimadzu, Japan). E. coli culture grown overnight in LB broth was brought to OD $0.1\left(\mathrm{~A}_{600}\right)$ with the same medium and further cultivated in the volume of $50 \mathrm{~mL}$ in $250 \mathrm{~mL}$ Erlenmeyer flasks on the shaker with agitation $\left(120 \mathrm{rpm}, 37^{\circ} \mathrm{C}\right)$. Genetically modified strains harboring resistance genes were grown in appropriate antibiotics concentrations (ampicillin 50 $\mu \mathrm{g} / \mathrm{mL}$, kanamycin $50 \mu \mathrm{g} / \mathrm{mL}$, hygromycin $100 \mu \mathrm{g} / \mathrm{mL}$ ).

\section{Protein expression conditions}

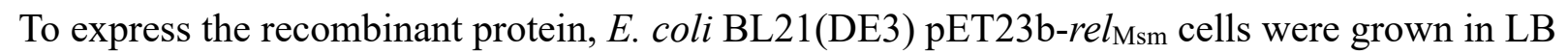
medium containing ampicillin $100 \mu \mathrm{g} / \mathrm{mL}$ until optical density $\mathrm{OD}_{600}$ of 0.6 was reached. Then cultures were supplemented with IPTG to a final concentration of $1 \mathrm{mM}$, followed by 3 hours incubation at $30^{\circ} \mathrm{C}$.

\section{Method Details}

626

\section{Construction of Bacterial Strains and Plasmids}

The list of the M. smegmatis and E. coli strains and plasmids used in this work is presented in Key Resources Table and Table S1. pMind-rel Msm $_{\text {and }}$ Mind-relZ

The rel $_{\text {Msm }}$ gene coding sequence was amplified by PCR with M. smegmatis $\mathrm{mc}^{2} 155$ as a template by using high-fidelity polymerase Phusion (Thermo Fisher Scientific) and primers rel Msm NdeI and rel Msm PacI listed in Table S1. Adenylate overhangs were added to amplified DNA fragment by incubation with Taq polymerase to allow cloning into intermediate vector pTZ57R via InsTAclone PCR Cloning Kit (Thermo Fisher Scientific). Insert in pTZ57R-rel Msm $_{\text {was sequenced }}$ using the primers pUC/M13 F, pUC/M13 R, rel Msm seq $1 \& 2$ shown in Table S1. Plasmids were purified from E.coli BMH pMind and BMH pTZ57R-rel $l_{\mathrm{Msm}}$ strains via alkaline lysis method, digested by NdeI and PacI restriction enzymes and separated by gel electrophoresis. Ligation, electroporation and selection procedures were performed by standard techniques and purified resultant vector pMind-rel $l_{\text {Msm }}$ was verified by restriction analysis with BamHI, PCR with Up pMind \& Low pMind primers and sequencing. Original or derived plasmids (pMind-0 or pMind-rel $l_{\text {Msm) }}$ were both transformed into M. smegmatis $\mathrm{mc}^{2} 155, \mathrm{mc}^{2} 155 \Delta \mathrm{rel}_{\mathrm{Msm}}, \mathrm{mc}^{2} 155 \Delta r e l_{\mathrm{Msm}} \Delta r e l \mathrm{Z}$ to study antibiotic targeting and E. coli RO91 harboring rpoS:lacZ chromosome fusion (Table S1) to verify the actual role of pMind-rel $l_{\mathrm{Msm}}$ plasmid in overexpression of $\mathrm{Rel}_{\mathrm{Msm}}$ protein, whose product (p)ppGpp is known to upregulate rpoS expression.

Mycobacterial expression plasmid capable of producing RelZ was obtained in a similar fashion but without an intermediate vector. PCR-generated fragment synthesized with SAS NdeI and SAS PacI primers and $\mathrm{mc}^{2} 155$ as a template was directly cloned into pMind plasmid. The resulting pMindrelZ plasmid was purified, tested by PCR and sequenced using Up/Low pMind and SAS seq 
primers, and then used for transformation of M. smegmatis wild-type strain as well as knockout strains mentioned above.

652 pET23b-rel Msm $_{\text {(His) }}$

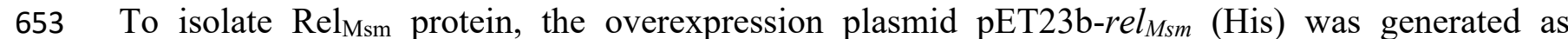
654 follows. Primers rel His NdeI and rel His HindIII (Table S1) were used to amplify rel $_{\text {Msm }}$ gene coding sequence by PCR with pTZ57R-rel $\mathrm{Msm}_{\mathrm{N}}$ as a template. The pET23b plasmid and produced DNA fragment were processed with NdeI and HindIII restriction endonucleases. Restriction products were purified from the agarose gel after electrophoresis, mixed with T4 DNA ligase and transferred into E. coli BMH. Resulting constructions were verified by PCR and sequencing with primers T7 promoter and T7 terminator (Novagen pET System Manual), as well as rel Msm seq 1\&2. T7 polymerase-expressing E. coli BL21(DE3) strain was transformed with the purified plasmid for overexpression.

rel $_{\text {Msm::luxAB reporter fusion. }}$

The rel $_{\text {Msm }}$ promoter is fused with the reporter genes $l u x A B$, including Shine-Dalgarno sequence and start codon, based on identified promoter sequence (Sureka et al., 2008). The $\operatorname{rel}_{\mathrm{Msm}} p::$ luxAB fusion was constructed on the basis of pKW08-Lx-Int plasmid that, along with $\operatorname{lux} A B$, also included int gene from mycobacteriophage L5 enabling the plasmid integration into the mycobacterial chromosome. We developed rel fus PciI and rel fus BamHI primers containing restriction sites (Table S1) to amplify rel $_{\text {Msm }}$ promoter region via PCR. The resulting DNA fragment was digested with appropriate restriction enzymes. To produce a vector with compatible ends, pKW08-Lx-Int plasmid containing double BamHI site was sequentially treated with BamHI and PciI restriction enzymes, resulting in three fragments:(i) PciI-BamHI $(4 \mathrm{~kb})$ containing plasmid origin and hygromycin resistance cassette; (ii) BamHI-BamHI (3,56 kb) containing lux genes; iii) PciI-BamHI $(1 \mathrm{~kb})$ containing tetRO cluster. Then the first fragment was used as a vector to clone the previously obtained PCR fragment. The resulting plasmid possessed a unique BamHI site but lacked lux genes. After BamHI digestion this plasmid was processed with alkaline phosphatase (CIAP) to prevent self-ligation and then ligated with the second fragment that contained lux genes. Produced transformants were selected by hygromycin resistance, and the correct orientation of the insert was verified by PCR with Low pMind and luxA Low primers. Resulting plasmid designated as pKW08-rel-Lx-Int was purified, verified by sequencing via luxA Low primer and transformed into M. smegmatis $\mathrm{mc}^{2} 155$ cells resulting in $\mathrm{mc}^{2} 155 \mathrm{rel}_{\mathrm{Msm}} \mathrm{p}:$ :lux strain.

679

680

\section{$\Delta$ rel $_{M s m}$ and $\Delta$ rel $_{M s m} \Delta$ relZ knockout strains}

The widely used two-step strategy was utilized to produce an unmarked rel $_{\text {Msm }}$ deletion strain of M. smegmatis (Parish and Stoker, 2000). This method involves several stages: generation of suicide plasmid vector containing rel $_{\mathrm{Msm}}$ deletion cassette cloned into p2NIL/pGOAL backbone, chromosome homologous recombination of non-replicating delivery plasmid introduced in mycobacteria, SacB negative selection for unmarked antibiotic-sensitive mutants. To produce $\mathrm{rel}_{\mathrm{Msm}}$ deletion cassette, $\mathrm{rel}_{\mathrm{Msm}}$ upstream and downstream areas were amplified by PCR with rel knock HindIII/rel knock SalI and rel knock NotI/rel knock PacI primers (Table S1), digested with restriction enzymes, sequentially cloned into p2NIL vector and PCR checked with Up/reUp p2NIL and Low/reLow p2NIL primers. The plasmid was purified from E.coli BMH cells and both insert areas were sequenced to avoid nucleotide replacements using Up/reUp/Low/reLow p2NIL primers. After that pGOAL19-PacI cassette was cloned to result in final suicide delivery plasmid p2NIL-rel ${ }_{\text {Msm }}[3 / 3]$. This plasmid was analyzed by BamHI restriction, purified and transformed into M.smegmatis $\mathrm{mc}^{2} 155$. Single cross-over transformants were selected by kanamycin and hygromycin and examined by X-Gal Blue-white screening. Sucrose resistant double cross-overs were selected by Blue-white screening, tested for antibiotic susceptibility, analyzed by PCR and sequencing with rel fus PciI and rel Msm Low primers, resulting in M. smegmatis mc $^{2} 155 \Delta$ rel strain. Knockout locus was amplified by PCR and sequenced using rel fus PciI and relMsm Low primers to confirm the presence of deletion and absence of nucleotide replacements in flanking genes. 
The same protocol was used to construct relZ deletion cassette. Flanking areas were amplified by PCR with SAS knock HindIII 2/ SAS knock BamHI 3 and SAS knock BglII/ SAS knock PacI primers, digested with restriction enzymes mentioned in primer names, cloned sequentially into p2NIL vector, the fidelity of the insert was verified by PCR and sequencing with Up/reUp p2NIL primers for the upstream fragment and with SAS NdeI and Low p2NIL for the downstream fragment. Then pGOAL19-PacI cassette was cloned to result in final suicide delivery plasmid p2NIL-relZ [3/3], the clones were selected by both kanamycin and hygromycin. This plasmid was analyzed by BamHI restriction, purified, and transformed to M. smegmatis $\mathrm{mc}^{2} 155$ and $\mathrm{mc}^{2} 155 \Delta \mathrm{rel}$ to produce single and double knockout strains. Knockout loci in both strains were amplified by PCR and sequenced using SAS His HindIII primer to confirm their genotypes.

\section{Cell Viability and Persister Cell Number}

Samples were regularly taken from batch culture of $M$. smegmatis $\mathrm{mc}^{2} 155$ grown under the standard conditions (See section Media and Growth Conditions); cells from these samples were spot-plated onto LB agar either immediately to count the total number of culturable cells or after preliminary exposure of the cells to an antibiotic for $24 \mathrm{~h}$ to count persister cells. For the latter, the samples (180 $\mu \mathrm{L}$ ) were transferred to wells of sterile 96 -well polystyrene microtiter plates and $20 \mu \mathrm{L}$ solutions of either DMNP in methanol or clinical antibiotics in water were added to the final concentrations (mM): 1.17 rifampicin (Rif), 0.094 tetracycline (Tetr), 0.0034 streptomycin (Str), $1.06 \mathrm{mM}$ DMNP. After $24 \mathrm{~h}$ cultivation at $37^{\circ} \mathrm{C}$, the cultures treated with antibiotics were diluted with saline and spot-plated. CFUs grown on plates after incubation at $37^{\circ} \mathrm{C}$ for $72 \mathrm{~h}$ were counted as persister cells. To study the character of killing curves specific for DMNP and antibiotics depending on the growth phase of cultures (Fig. 2), M. smegmatis cells were grown under the standard conditions (See section Media and Growth Conditions) to reach the exponential phase $\left(\mathrm{A}_{600} \approx 0.5\right)$ or the stationary phase $\left(\mathrm{A}_{600} \approx 3.2\right)$. The cells sampled at these growth phases $(180 \mu \mathrm{L})$ were transferred to wells of sterile 96-well polystyrene microtiter plates and $20 \mu \mathrm{L}$ solutions of either DMNP in methanol or clinical antibiotics in water were added to the final concentrations (mM): 1.17 rifampicin (Rif), 0.094 tetracycline (Tetr), 0.003 streptomycin (Str), $1.06 \mathrm{mM}$ DMNP. The cells were further cultivated for $72 \mathrm{~h}$ at $37^{\circ} \mathrm{C}$. At the designated time points (Figure 3) the samples were taken, diluted with saline and spot-plated. CFUs grown on plates after incubation at $37^{\circ} \mathrm{C}$ for $72 \mathrm{~h}$ were counted as survival cells.

\section{Overexpression Assays}

M. smegmatis $\mathrm{mc}^{2} 155$ strains transformed with pMind-rel $l_{\mathrm{Msm}}$ or pMind-relZ plasmids were grown overnight under the standard conditions (See section Media and Growth Conditions), except 50 $\mu \mathrm{g} / \mathrm{mL}$ kanamycin was added to the medium along with ampicillin. The grown cultures of each strain $(50 \mathrm{~mL})$ were transferred to two Erlenmeyer flasks $(250 \mathrm{~mL})$. To induce rel $_{\mathrm{Msm}}$ or relZ overexpression, $42 \mathrm{nM}$ solution of tetracycline was added to one of two flasks of each strain (induced cells), whereas the second was kept as the control (uninduced cells). Cells taken in the volume of $180 \mu \mathrm{L}$ from both induced and uninduced batch cultures of each strain at the onset of cell transition to stationary phase ( $6 \mathrm{~h}$ of observation) were transferred to the wells of microtiter plates. Then $20 \mu \mathrm{L}$ solutions of either DMNP diluted in methanol or clinical antibiotics (where necessary) diluted in water were added to both of them at final concentrations designated in Figures. $M$. smegmatis culture with added $20 \mu \mathrm{L}$ of methanol served as the control for DMNP samples. The microtiter plates were then cultivated at $37^{\circ} \mathrm{C}$ for $24 \mathrm{~h}$ and the cells taken from the wells were diluted with saline and spot-plated onto LB agar to enumerate CFUs grown after $72 \mathrm{~h}$ of cultivation. 
748 Cell energy state in batch cultures of M. smegmatis was characterized by cell adenylate pools (ATP, 749 ADP and AMP) determined by HPLC-UV method specially developed for this object (Akhova and

\section{His-tag RelMsm Protein Purification and DMNP Activity Assays}

The overexpression of rel $_{\text {Msm }}$ was induced by the supplementation of E. coli BL21DE3 pET23b$\mathrm{rel}_{\mathrm{Msm}}$ cells with IPTG to a final concentration of $1.0 \mathrm{mM}$. Recombinant His-tag protein was purified with FPLC chromatography in accordance with the standard procedures (Coligan, 1996). To study effect of purified Rel $\mathrm{Msm}_{\text {sm }}$ protein on DMNP activity, M. smegmatis $\mathrm{mc}^{2} 155$ cells were grown under the standard conditions. Aliquots of cells $(180 \mu \mathrm{L})$ were taken from the culture after 6 , 12 and $24 \mathrm{~h}$ of cultivation, transferred to the wells of sterile 96-well polystyrene microtiter plates, supplemented $\left(\mathrm{Rel}^{+}\right)$or not $\left(\mathrm{Rel}^{-}\right)$with a $5 \mu \mathrm{L}$ of a purified $\operatorname{Rel}_{\mathrm{Msm}}$ protein solution $(1 \mu \mathrm{g} / \mathrm{mL})$, then a methanol solution of DMNP $(20 \mu \mathrm{L})$ was added to both at the final concentrations (mM) $0.86,0.96$, 1.06. The bovine serum albumin (BSA) was used as an unspecific control at the same concentration as $\mathrm{Rel}_{\mathrm{Msm}}$. The microtiter plates were then cultivated at $37^{\circ} \mathrm{C}$ for $24 \mathrm{~h}$, the cells taken from the wells were diluted with saline and spot-plated onto LB agar to enumerate CFUs grown after $72 \mathrm{~h}$ of cultivation.

\section{RelMsm (p)ppGpp Synthesizing Activity Depending on DMNP Assays}

In vitro (p)ppGpp synthesizing activity of purified Rel $\mathrm{l}_{\mathrm{Msm}}$ was measured under the standard conditions with no supplementation or with the following supplementations: $5 \%$ methanol or DMNP dissolved in 5\% methanol to the final concentrations specified in Figure 5. The (p)ppGpp synthesizing activity was assayed using a slightly modified method by Wexselblatt et al. (Wexselblatt et al., 2010). 5x reaction mixture containing $2.0 \mathrm{mM} \mathrm{GTP}, 20 \mathrm{mM}$ ATP, $200 \mathrm{mM}$ Tris- $\mathrm{HCl}$ (pH 7.4), $5 \mathrm{mM}$ DTT, $50 \mathrm{mM} \mathrm{MgCl} 2,50 \mathrm{mM} \mathrm{KCl}, 135 \mathrm{mM}\left(\mathrm{NH}_{4}\right)_{2} \mathrm{SO}_{4}$ was freshly prepared. $50-200 \mu \mathrm{g} / \mathrm{mL} \mathrm{Rel}_{\mathrm{Msm}}$ together with $1 \mathrm{x}$ reaction mixture were mixed in a total volume of 0.5-1.0 mL. The reactions were incubated at $37^{\circ} \mathrm{C}$ for a period of 1-4 hours and stopped by the addition of $0.4 \mathrm{~N} \mathrm{HClO}_{4}$. The samples were analyzed by HPLC-UV method (UV detection at 254 $\mathrm{nM}$ ) developed by us (Akhova and Tkachenko, 2019), except the mobile phase used consisted of acetonitrile (A) and $50 \mathrm{mM}$ aqueous monobasic potassium phosphate $(\mathrm{pH} \mathrm{4.6)}$ (B) in a ratio of $0.5(\mathrm{~A}) / 99.5(\mathrm{~B})$. Rel $\mathrm{M}_{\text {Msm }}$ activity is quantified by the decrease in the concentration of the substrate (GTP) per $1 \mu$ mole of the protein per 1 hour. To verify the DMNP effect on the (p)ppGpp synthetase activity, it was added to the reaction mixture in the concentrations specified in the legends to Figures. 


\section{Molecular Docking Assay}

Since the substrate interaction data are not yet available for Rel $\mathrm{M}_{\mathrm{Mtb}}$ structure, GTP pose in the Rel $\mathrm{Mtb}_{\mathrm{m}}$ active site was calculated using AutoDock Vina (Trott and Olson, 2010). The lack of data regarding the amino acids that contribute to the binding of GDP/GTP molecules in the active site of Rel $\mathrm{Mtb}_{\mathrm{m}}$ protein prompted us to screen for such an information in Rel proteins from different species. We used the X-ray structure data showing GDP interaction with Relseq from Streptococcus dysgalactiae subsp. equisimilis (PDB ID 1VJ7) (Hogg et al., 2004), which showed several amino acid residues contributing to the GDP-Relseq binding through Rel proteins ClustalX alignment (Larkin et al., 2007). The corresponding amino acids from Rel $_{\mathrm{Mtb}}$ were utilized to localize GTP/GDP binding site. The binding pocket has been centered using AutoDock Vina to take into account amino acid residues Y300, Y309, H313, Q327 (Mtb numbers), which deemed crucial for the Rel $\mathrm{M}_{\mathrm{Mtb}}$ interaction with GTP/GDP. These include Y309 and H313 from Syn3 responsible for guanosine moiety interaction in various species (Steinchen and Bange, 2016) and $Y 300$ and Q327 according to the crystal structure of RelSeq where GDP interactions have been shown. Thus, the box center was set to $147,154,-14$ for $\mathrm{x}, \mathrm{y}, \mathrm{z}$ respectively and box size was set at $20 \AA$ for all directions with $0.375 \AA$ spacing parameter to cover all the amino acids mentioned and to include adjacent residues only. We run a series of blind docking calculations using Achilles Blind Docking Server (Sanchez-Linares et al., 2012), a tool specialized for such purposes, to find yet unknown DMNP binding sites. ProteinLigand Interaction Profiler (Salentin et al., 2015) was utilized to analyze interactions in protein-ligand complexes (Fig 5B \& 5D). PyMOL was used for visual analysis of the docking site and for merging results of the substrate and the inhibitor dockings. To reveal the similarities of the DMNP binding sites in Rel $\mathrm{M}_{\mathrm{Mtb}}$ and RelP proteins, we performed BLASTp alignment of their amino acid sequences. To visualize the structure of $\mathrm{Rel}_{\mathrm{Msm}}$ protein, we merged the $\mathrm{Rel}_{\mathrm{Mtb}} \mathrm{N}$-terminal domain from the crystal structure (PDB ID 5XNX) with the C-terminal domain structure calculated

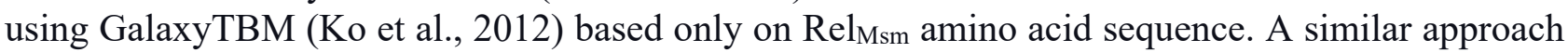
was applied to predict M. smemgatis RelZ structure: we merged S. aureus RelP structure (PDB ID 6EWZ) with computationally obtained structure of RNase HII domain from RelZ.

\section{Antibiotic Susceptibility and Biofilm-Eradication Assays $M I C, M B C, M B E C$}

To determine the Minimal Inhibitory Concentration (MIC), Minimal Bactericidal Concentration (MBC) and Minimal Biofilm Eradication Concentration (MBEC) for tetracycline, streptomycin, rifampicin, isoniazid, ethambutol, and DMNP (Table S2), the Calgary system with 96-well plates

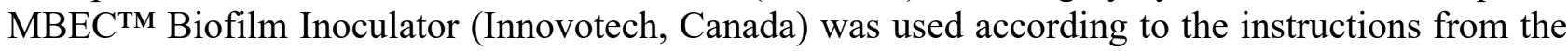
manufacturer and the method by Garrison and Huigens (Ceri et al., 1999; Garrison and Huigens, 2017).

\section{Complex effect of DMNP and clinical antibiotics on M. smegmatis survival assays}

M. smegmatis $\mathrm{mc}^{2} 155$ cells grown in $5 \mathrm{~mL}$ of Middlebrooke medium with addition of $5 \mu \mathrm{g} / \mathrm{mL}$ ampicillin and $0.05 \%$ Tween 80 in thermo-shaker GFL1092 (GFL, Germany) (200 rpm, 37 $\left.{ }^{\circ} \mathrm{C}\right)$ to optical density of $1.5\left(\mathrm{~A}_{600}\right)$ were transferred in the volume of $180 \mu \mathrm{L}$ to the wells of sterile 96 -well polypropylene microtiter plates, to which streptomycin or rifampicin were added in the volume of $20 \mu \mathrm{L}$ to final concentration (x MIC) of $0.0 ; 1.0 ; 2.0 ; 5.0$ for streptomycin (at $\mathrm{MIC}=0.137 \mu \mathrm{M}$ ) and $0 ; 1 ; 5 ; 10 ; 20$ for rifampicin (at MIC $=5.83 \mu \mathrm{M}$ ). The cultures with no addition of DMNP (control) or with an addition of $20 \mu \mathrm{L}$ of methanol (met) were used as the controls. The cultures in wells were then cultivated in the microplate reader Infinite M200 (Tecan, Autsria) under $37^{\circ} \mathrm{C}$ with every hour agitation $(15 \mathrm{sec})$ and measuring the optical density. After $24 \mathrm{~h}$ the samples from each of the wells were taken and spot-plated to encounter the number of survival cells. Then $10 \mu \mathrm{L}$ of the methanol DMNP solution were added to the same wells to achieve the final concentrations designated in Figures and the cultures were further cultivated for $24 \mathrm{~h}$ under the same conditions. The cultures treated with antibiotics were diluted with saline and spot-plated. CFUs grown on plates after incubation at $37^{\circ} \mathrm{C}$ for $72 \mathrm{~h}$ were counted as persister cells. 


\section{Effects of DMNP or clinical antibiotics on biofilm formation}

847 M. smegmatis $\mathrm{mc}^{2} 155$ cells grown under the standard conditions were washed with fresh 848 Middlebrook 7H9 with no addition of Tween 80 . To produce biofilm, washed cells were inoculated 849 into the same medium and the resultant culture $(180 \mu \mathrm{L})$ was transferred to the wells of sterile 96850 well polypropylene microtiter plates. Methanol DMNP solution or water solutions of clinical antibiotics were added to the cultures in $20-\mu \mathrm{L}$ volumes to the final concentrations specified in Figures. The samples $(180 \mu \mathrm{L})$ of $M$. smegmatis culture with no additions (contr) or with the addition of $20 \mu \mathrm{L}$ of methanol (met) served as the controls. Plates were then cultivated at $37^{\circ} \mathrm{C}$ for $48 \mathrm{~h}$ with no agitation. To assess the antibiotic effects on biofilm formation, liquid planktonic cultures were carefully removed from under the pellicles to avoid their damaging. Pellicles were then dried and the levels of biofilm formation were assessed via the conventional staining with $0.1 \%$ crystal violet. Optical density $\left(\mathrm{A}_{570}\right)$ of the stained ethanol extracts was then measured using microplate reader Infinite M200 (Tecan, Austria). Growth conditions and antibiotic concentrations for studying planktonic cells were the same as for biofilm formation, except the Middlebrook $7 \mathrm{H} 9$ medium supplemented with Tween 80 . To assess the cell survival, cells taken from the planktonic cultures grown for $48 \mathrm{~h}$ were spot-plated onto LB agar and the CFU number was calculated.

\section{Effect of DMNP on M. smegmatis Pellicle Formation}

M. smegmatis forms architecturally complex biofilms (pellicles) at the air/liquid interface of standing cultures. To investigate the pellicle structure and susceptibility of biofilm formation to DMNP, cells of parental strain M. smegmatis $\mathrm{mc}^{2} 155$ (WT) and its rel $_{\mathrm{Ms} m}$ and relZ knockout- and overexpressing derivatives grown with the standard procedure were washed out by centrifugation (16g X $5 \mathrm{~min}$ ) with Middlebrook $7 \mathrm{H} 9$ medium with no Tween 80 and transferred to $5 \mathrm{~mL}$ (final volume) of the same medium containing DMNP in concentrations designated in figures to initial optical density of $0.1\left(\mathrm{~A}_{600}\right)$ measurement. Resultant medium with inoculated cells was then placed in preliminary weighted polystyrene plates $(\varnothing 40 \mathrm{~mm})$. Cells were grown with no agitation at $37^{\circ} \mathrm{C}$ for $72 \mathrm{~h}$. Plates were photographed, liquid planktonic cultures were carefully removed from under the pellicles to avoid their damaging and pellicles inside the plates were then dried at $37^{\circ} \mathrm{C}$ to constant weights that were used as the values of pellicle mass (p.m.). Just after removing planktonic cultures their biomass and cell viability were assessed by optical density $\left(\mathrm{A}_{600}\right)$ measurement and spot-plating, respectively.

\section{Cell Sliding Motility and Colony Morphology}

To evaluate DMNP activity against $M$. smegmatis $\mathrm{mc}^{2} 155$ sliding motility, cells were grown overnight under the standard conditions. The culture was then brought with the same medium to optical density of $0.4\left(\mathrm{~A}_{600}\right)$ and $3 \mu \mathrm{L}$ of resultant cell suspension were inoculated onto the surface of Middlebrook $7 \mathrm{H} 9$ medium solidified with $0.3 \%$ agarose $(\mathrm{w} / \mathrm{v})$ into the center of plate $(\varnothing 40$ $\mathrm{mm}$ ). Then either DMNP dissolved in methanol to the final concentrations specified in the Figures or pure methanol (control) were added in the volume of $50 \mu \mathrm{L}$ to the medium during its preparation. Plates were cultivated at $37^{\circ} \mathrm{C}$ for $40 \mathrm{~h}$ and photographed with a digital camera (Olympus, Japan) to process the grown sliding colonies. The colony density was described by colony integrated optical density. Processing included the measuring of the sliding colony area $\left(\mathrm{mm}^{2}\right)$ and its optical density (absorbance units (a.u.)). A colony area was measured by counting the pixel number within the colony region. The values of a specific optical density (SOD) calculated for sliding areas as a ratio of optical density to colony area (a.u. $/ \mathrm{mm}^{-2}$ ) were used to differentiate the inhibition of sliding motility from the killing effect of DMNP (explanations are given in section Results/). To evaluate probable effect of DMNP on colony morphology, M. smegmatis $\mathrm{mc}^{2} 155$ parent strain (WT) and its knockout derivatives $\left(\Delta r e l_{\mathrm{Msm}}\right.$ or $\left.\Delta r e l_{\mathrm{Msm}} \Delta r e l \mathrm{Z}\right)$ were grown as above (this section) and each of cultures in the volume of $2 \mu \mathrm{L}\left(\mathrm{A}_{600}=1.0\right)$ were inoculated into the center of the medium surface of each of two plates $(\varnothing 40 \mathrm{~mm})$ with agarized $(0.3 \%)$ Middlebrook $7 \mathrm{H} 9$ medium, one of which contained $0.02 \mathrm{mM}$ DMNP, while another kept with no additions (conrol), cultivated $\left(37^{\circ} \mathrm{C}\right)$ for 72 h. To make the macrophoto of colonies, Olympus c-3040 zoom camera (Japan) was used with 
maximal multiplication. Micro photos of the colony edges were produced with microscope MICMED 6 (LOMO, Russia) equipped with digital camera MC-6.3 (LOMO, Russia).

\section{Zeta Potential}

To determine the bacterial cell surface charge (Bayer and Sloyer, 1990), cells were washed with $1 \mathrm{mM}$ PBS, brought with the $10 \mathrm{mM}$ potassium phosphate buffer to optical density of $0.3\left(\mathrm{~A}_{650}\right)$ and Zeta potential $(\zeta)$ of cell suspension was measured with zetameter Zetasizer Nano S (Malvern Instruments Ltd, UK).

\section{Hydrophobicity Assay}

The protocol for the hydrophobicity assay was adapted from that of Rosenberg (Rosenberg, 2006). Briefly, M. smegmatis $\mathrm{mc}^{2} 155$ cells grown under the standard conditions to optical density of 0.8 $\left(\mathrm{A}_{600}\right)$ were exposed to antibiotics at $37^{\circ} \mathrm{C}$ for $5 \mathrm{~h}$, washed in PBS, and $300 \mu \mathrm{L}$ of cell suspensions were mixed with $30 \mu \mathrm{L}$ of hexadecane. The mixture was then vortexed for $30 \mathrm{sec}$ and allowed to settle at room temperature for $15 \mathrm{~min}$. The aqueous phase $(150 \mu \mathrm{L})$ was then carefully removed, and its optical density $\left(\mathrm{A}_{600}\right)$ was measured in microplate reader Infinite M200 (Tecan, Austria). The percentage of cell hydrophobicity was calculated as follows: Cell hydrophobicity $=\left[1-\left(\mathrm{A}_{600}\right.\right.$ final/ A 600 initial)] x 100.

\section{Chemical synthesis}

\section{Materials and general methods}

The NMR spectra were recorded in $\mathrm{CDCl}_{3},{ }^{1} \mathrm{H}$ at $400 \mathrm{MHz}$ and ${ }^{13} \mathrm{C}$ at $100.6 \mathrm{MHz}$ with $\mathrm{CDCl}_{3}(\delta$ $7.26,{ }^{1} \mathrm{H} ; \delta 77.0,{ }^{13} \mathrm{C}$;) as an internal standard unless otherwise indicated. Various $2 \mathrm{D}$-techniques and DEPT experiments were used to establish the structures and to assign the signals. The mass spectra were measured on a Thermo Exactive (Orbitrap), where the spectra were recorded in a positive or negative ion mode using electrospray ionization (ESI) from methanol or acetonitrile. All reactions were performed under an atmosphere of dry, oxygen-free nitrogen in oven-dried glassware. Yields are given for isolated products showing one spot on a TLC plate and no impurities detectable in the NMR spectrum. The identity of the products prepared by different methods was checked by comparison of their NMR spectra.

Reaction progress was monitored by GC/MS analysis and thin layer chromatography (TLC) on aluminum backed plates with Merck Kiesel 60 F254 silica gel. TLCs were either visualized by UV irradiation at $254 \mathrm{~nm}$ or stained by exposure to an ethanolic solution of phosphomolybdic acid. Purification by column chromatography was carried out using Merck Kiesel $60 \mathrm{H}$ silica adsorbent. All solvents and reagents for the reactions were of reagent grade and were dried and distilled under argon immediately before use.

(E)-3-(2-bromo-3-methylphenyl)-2-methylacrylaldehyde (3) and Z-crotyltrichlorosilane (4) were synthesized following published protocol by Malkov (Incerti-Pradillos et al., 2016); 1,6-Dimethyl1,2-dihydronaphthalene and methyl (E)-2-diazo-3-pentenoate were synthesized by the method of Davies (Davies and Walji, 2005). Catalyst MAKDIOX was synthesized by the method of Malkov (Fukazawa et al., 2019; O'Hora et al., 2015) All spectral data were in agreement with literature. Copies of ${ }^{1} \mathrm{H}$ and ${ }^{13} \mathrm{C}$ NMR spectra of $(-)-2$ are presented in Table S7.

\section{Asymmetric synthesis of (-)-(R)-4-((1S,4R)-4,7-dimethyl-1,2,3,4-tetrahydronaphthalen-1- yl)pentanoic acid (DMNP).}

(-)-(3R,4S,E)-1-(2-bromo-3-methylphenyl)-2,4-dimethlhexa-1,5-dien-3-ol (5): A $100 \mathrm{~mL}$ round bottom flask fitted with a magnetic stirring bar was flame-dried, evacuated and backfilled with $\mathrm{N}_{2}$. The flask was charged with $30 \mathrm{~mL}$ of dry propionitrile and successively with a solution of MAKDIOX (80.4 mg, $0.1 \mathrm{mmol}, 2 \mathrm{~mol} \%$ ), aldehyde 3 (1.25 g, $5.2 \mathrm{mmol}, 1$ eq.) and Hünig's base (1.8 mL, $10.3 \mathrm{mmol}, 2$ eq.) in $1 \mathrm{~mL}$ of dry propionitrile each. The solution was cooled at $-60{ }^{\circ} \mathrm{C}$ 
and a solution of Z-crotyltrichlorosilane 4 ( $1.7 \mathrm{~g}, 8.9 \mathrm{mmol}, 1.7 \mathrm{eq}$.) in $1 \mathrm{~mL}$ of dry propionitrile was added dropwise to the reaction mixture. The mixture was stirred at this temperature for two days. After that time, it was quenched with a saturated solution of $\mathrm{NaHCO}_{3}(10 \mathrm{~mL})$, washed with $20 \mathrm{~mL}$ of $\mathrm{NaHCO}_{3}$ and extracted with DCM $(3 \times 60 \mathrm{~mL})$. Combined organic layers were dried over $\mathrm{Na}_{2} \mathrm{SO}_{4}$ and solvent was removed in vacuo. Flash chromatography on silica with a gradient eluent system (100\% hexane to 95:5, hexane/ethyl acetate) afforded the target homoallylic alcohol (-)-5 as a colourless oil $\left(1.10 \mathrm{~g}, 72 \%\right.$ yield). ${ }^{1} \mathrm{H}$ NMR $\left(400 \mathrm{MHz}, \mathrm{CDCl}_{3}\right): \delta_{\mathrm{H}} 1.13(\mathrm{~d}, J=6.8 \mathrm{~Hz}, 3 \mathrm{H}) ; 1.70$ $(\mathrm{s}, 3 \mathrm{H}) ; 1.73$ (sbroad, $1 \mathrm{H}) ; 2.43(\mathrm{~s}, 3 \mathrm{H}) ; 2.53(\mathrm{q}, J=6.8 \mathrm{~Hz}, 1 \mathrm{H}) ; 4.08(\mathrm{~d}, J=6.4 \mathrm{~Hz}, 1 \mathrm{H}) ; 5.06-5.15$ $(\mathrm{m}, 2 \mathrm{H})$; 5.83-5.91 (m, 1H); $6.53(\mathrm{~s}, 1 \mathrm{H})$; 7.04-7.06 (m, 1H); 7.11-7.17 (m, 2H). In agreement with literature. (Incerti-Pradillos et al., 2016) Chiral HPLC (Chiralpak IA-3, hexane/2-propanol = 98:2, $0.75 \mathrm{~mL} / \mathrm{min}$, UV detection at $225 \mathrm{~nm}$ ) showed $99: 1$ e.r. $\left(t_{\mathrm{R}}=19.3 \mathrm{~min}\right.$ (major), $t_{\mathrm{S}}=20.8 \mathrm{~min}$ (minor)).

In the racemic variant: $Z$-crotyltrichlorosilane 4 (11.34 g, $60 \mathrm{mmol}, 1.2$ eq.) was added to a solution of 3 (11.9 g, $50 \mathrm{mmol}, 1 \mathrm{eq})$ in DMF $(150 \mathrm{~mL})$ and Hünig's base (20.86 mL, $120 \mathrm{mmol}, 2$ eq.) under $\mathrm{N}_{2}$ atmosphere. The reaction mixture was stirred and monitored by TLC until completion. Then it was quenched with saturated $\mathrm{NaHCO}_{3}(100 \mathrm{~mL})$ and extracted with ethyl acetate $(3 \times 200$ $\mathrm{mL}$ ). The organic layers were dried over $\mathrm{Na}_{2} \mathrm{SO}_{4}$ and concentrated in vacuo. Flash chromatography on silica with a gradient eluent system (100\% hexane to 95:5, hexane/ethyl acetate) afforded the target homoallylic alcohol $( \pm)-5$ as a colourless oil (12.5 g, $85 \%) .{ }^{1} \mathrm{H}$ NMR data matched those in the chiral version.

(2E,4R,5S,7E)-Methyl 5-(2-bromo-3-methylphenyl)-4-methylnona-2,7-dienoate (6): A $\quad 30 \%$ suspension of KH in mineral oil $(2.2 \mathrm{~g}, 55.5 \mathrm{mmol}, 3$ eq. $)$ was washed with anhydrous DME ( $3 \times 10$ $\mathrm{mL})$. Anhydrous DME (45 mL) was added to the KH. Alcohol (-)-5 (1.10 g, $3.7 \mathrm{mmol}, 1$ eq.) and 18-crown-6 (0.97 g, $3.7 \mathrm{mmol}, 1 \mathrm{eq}$.) were successively added to the solution and the mixture was stirred for two days at rt. The solution was cooled to $-78^{\circ} \mathrm{C}$ and quenched with a $1 \mathrm{M}$ solution of 2,4,6-tri-tert-butylphenol in dry DME (3.5 eq). The solution was poured into a saturated solution of $\mathrm{NH}_{4} \mathrm{Cl}(50 \mathrm{~mL})$ and extracted with DCM $(3 \times 50 \mathrm{~mL})$. The combined organic layers were dried over $\mathrm{Na}_{2} \mathrm{SO}_{4}$ and concentrated in vacuo. The resulting crude aldehyde obtained as a yellow oil was used immediately in the next step.

$\mathrm{LiCl}$ (186.5 mg, $4.44 \mathrm{mmol}, 1.2$ eq.) was weighted in a $50 \mathrm{~mL}$ flame-dried round bottom flask. The flask was evacuated and backfilled with $\mathrm{N}_{2}$. Dry $\mathrm{CH}_{3} \mathrm{CN}(10 \mathrm{~mL})$ was added followed by a solution of Hünig's base ( $0.8 \mathrm{~mL}, 4.44 \mathrm{mmol}, 1.2$ eq.) and trimethyl phosphonoacetate $(0.9 \mathrm{~mL}, 4.44 \mathrm{mmol}$, 1.2 eq.) in $2 \mathrm{~mL}$ of dry $\mathrm{CH}_{3} \mathrm{CN}$ each. After stirring the mixture for 5 minutes, the crude aldehyde (3.7 mmol, 1 eq.) in $2 \mathrm{~mL}$ of anhydrous $\mathrm{CH}_{3} \mathrm{CN}$ was added dropwise. The reaction mixture was stirred overnight at $\mathrm{rt}$ and after that time it was quenching with a saturated solution of $\mathrm{NH}_{4} \mathrm{Cl}(20$ $\mathrm{mL})$. The mixture was extracted with DCM $(3 \times 50 \mathrm{~mL})$, the organic phases dried over $\mathrm{Na}_{2} \mathrm{SO}_{4}$ and the solvents removed under reduced pressure. The crude mixture of diastereoiomers was separated by flash column chromatography on silica eluting with a gradient system (100\% petroleum ether to 30:1 petroleum ether/ethyl acetate) to yield in order of elution $\boldsymbol{e p i - 6}$ as a colourless oil ( $0.3 \mathrm{~g}, 23 \%)$ and 6 as a colourless oil $(0.7 \mathrm{~g}, 51 \%$ yield over two steps).

6: ${ }^{1} \mathrm{H}$ NMR (400 MHz, $\left.\mathrm{CDCl}_{3}\right): \delta_{\mathrm{H}} 1.05(\mathrm{~d}, J=6.8 \mathrm{~Hz}, 3 \mathrm{H}), 1.56(\mathrm{dd}, J=6.3,1.4 \mathrm{~Hz}, 3 \mathrm{H}), 2.37(\mathrm{t}, J$ $=6.7 \mathrm{~Hz}, 2 \mathrm{H}), 2.45(\mathrm{~s}, 3 \mathrm{H}), 2.72(\mathrm{~m}, 1 \mathrm{H}), 3.54(\mathrm{~m}, 1 \mathrm{H}), 3.73(\mathrm{~s}, 3 \mathrm{H}), 5.25(\mathrm{~m}, 1 \mathrm{H}), 5.40(\mathrm{~m}, 1 \mathrm{H})$, $5.77(\mathrm{dd}, J=15.7,1.4 \mathrm{~Hz}, 1 \mathrm{H}), 7.00(\mathrm{~m}, 2 \mathrm{H}), 7.13(\mathrm{~m}, 2 \mathrm{H}) .{ }^{13} \mathrm{C} \mathrm{NMR}\left(100 \mathrm{MHz}, \mathrm{CDCl}_{3}\right)$ : $\delta_{\mathrm{C}} 14.6$, $17.3,24.1,33.1,39.5,47.5,50.8,119.7,125.8,126.5,127.8,128.2,138.1,141.1,152.3,166.6$

epi-6: ${ }^{1} \mathrm{H}$ NMR $\left(400 \mathrm{MHz}, \mathrm{CDCl}_{3}\right): \delta_{\mathrm{H}} 0.97(\mathrm{~d}, J=6.8 \mathrm{~Hz}, 3 \mathrm{H}), 1.50(\mathrm{dd}, J=6.3,1.4 \mathrm{~Hz}, 3 \mathrm{H}), 2.18$ $(\mathrm{m}, 1 \mathrm{H}), 2.43(\mathrm{~s}, 3 \mathrm{H}), 2.53(\mathrm{~m}, 1 \mathrm{H}), 3.41(\mathrm{~m}, 1 \mathrm{H}), 3.74(\mathrm{~s}, 3 \mathrm{H}), 5.15(\mathrm{~m}, 1 \mathrm{H}), 5.26(\mathrm{~m}, 1 \mathrm{H}), 5.82$ $(\mathrm{dd}, J=15.7,1.4 \mathrm{~Hz}, 1 \mathrm{H}), 6.96(\mathrm{~m}, 2 \mathrm{H}), 7.09(\mathrm{~m}, 1 \mathrm{H}), 7.16(\mathrm{~m}, 1 \mathrm{H}) .{ }^{13} \mathrm{C} \mathrm{NMR}\left(100 \mathrm{MHz}, \mathrm{CDCl}_{3}\right)$ : $\delta_{\mathrm{C}} 17.3,17.5,24.1,37.7,41.8,48.2,50.9,120.2,125.0,126.1,127.4,128.1,138.0,141.8,152.4$, 166.4 
The racemic variant: A 30\% suspension of $\mathrm{KH}$ in mineral oil (16.4 g, $123 \mathrm{mmol}, 3$ eq.) was washed with anhydrous THF $(3 \times 50 \mathrm{~mL})$. Anhydrous THF $(200 \mathrm{~mL})$ was added to the KH. Alcohol $( \pm)-5$ (12 g, $41 \mathrm{mmol}, 1$ eq.) and 18-crown-6 (10.82 g, $41 \mathrm{mmol}, 1$ eq.) were successively added to the solution and the mixture was stirred for $48 \mathrm{~h}$ at rt. The solution was cooled to $-78{ }^{\circ} \mathrm{C}$ and quenched with a $1 \mathrm{M}$ solution of 2,4,6-tri-tert-butylphenol (3.5 eq) in dry DME. The mixture was poured into a saturated solution of $\mathrm{NH}_{4} \mathrm{Cl}(200 \mathrm{~mL})$ and extracted with DCM $(3 \times 200 \mathrm{~mL})$. The combined organic layers were dried over $\mathrm{Na}_{2} \mathrm{SO}_{4}$ and concentrated in vacuo. The resulting crude aldehyde obtained as a yellow oil was used immediately in the next step.

$\mathrm{LiCl}$ (2.09 mg, $49.2 \mathrm{mmol}, 1.2$ eq.) was weighted in a $250 \mathrm{~mL}$ flame-dried round bottom flask. The flask was evacuated and backfilled with $\mathrm{N}_{2}$. Dry $\mathrm{CH}_{3} \mathrm{CN}(100 \mathrm{~mL})$ was added followed by a solution of Hünig's base $(8.57 \mathrm{~mL}, 49.2 \mathrm{mmol}, 1.2$ eq.) and trimethyl phosphonoacetate $(7.96 \mathrm{~mL}$, $49.2 \mathrm{mmol}, 1.2$ eq.) in $20 \mathrm{~mL}$ of dry $\mathrm{CH}_{3} \mathrm{CN}$ each. After stirring the mixture for 5 minutes, the crude aldehyde (1 eq.) in $50 \mathrm{~mL}$ of anhydrous $\mathrm{CH}_{3} \mathrm{CN}$ was added dropwise. The reaction mixture was stirred overnight at $\mathrm{rt}$ and after that time it was quenching with a saturated solution of $\mathrm{NH}_{4} \mathrm{Cl}$ $(100 \mathrm{~mL})$. The mixture was extracted with DCM $(3 \times 200 \mathrm{~mL})$, the organic phases dried over $\mathrm{Na}_{2} \mathrm{SO}_{4}$ and the solvents removed under reduced pressure. The crude mixture was purified by flash column chromatography on silica eluting with a gradient system (100\% petroleum ether to $30: 1$ petroleum ether/ethyl acetate) to yield $( \pm)-6$ as a colourless oil (7.6 g, $53 \%$ yield over two steps). ${ }^{1} \mathrm{H}$ NMR data matched those in the chiral version.

(R,E)-methyl 4-((1S,4R)-8-bromo-4,7-dimethyl-1,2,3,4-tetrahydronaphthalen-1-yl)pent-2-enoate (7): Methanesulfonic acid $(0.37 \mathrm{~mL}, 5.7 \mathrm{mmol}, 3$ eq.) was added to a solution of $6(693 \mathrm{mg}, 1.9$ mmol, 1 eq.) in $\mathrm{CHCl}_{3}(3 \mathrm{~mL})$ and the reaction mixture was stirred at $40{ }^{\circ} \mathrm{C}$ for two days. The reaction was quenched with saturated $\mathrm{NaHCO}_{3}(5 \mathrm{~mL})$ and extracted with $\mathrm{CH}_{2} \mathrm{Cl}_{2}(3 \times 20 \mathrm{~mL})$. The combined organic layers were dried over $\mathrm{Na}_{2} \mathrm{SO}_{4}$ and concentrated in vacuo. Purification by column chromatography on silica (eluting with 95:5 petroleum ether/ethyl acetate) gave the title compound 7 as a colourless oil $(570 \mathrm{mg}, 83 \%$ yield $) .{ }^{1} \mathrm{H}$ NMR $\left(400 \mathrm{MHz}, \mathrm{CDCl}_{3}\right): \delta_{\mathrm{H}} 0.93(\mathrm{~d}, J=6.9 \mathrm{~Hz}, 3 \mathrm{H})$, $1.26(\mathrm{~d}, J=6.9 \mathrm{~Hz}, 3 \mathrm{H}), 1.92(\mathrm{~m}, 4 \mathrm{H}), 2.40(\mathrm{~s}, 3 \mathrm{H}), 2.79(\mathrm{~m}, 1 \mathrm{H}), 3.08(\mathrm{~m}, 1 \mathrm{H}), 3.54(\mathrm{~m}, 1 \mathrm{H}), 3.73$ $(\mathrm{s}, 3 \mathrm{H}), 5.77(\mathrm{dd}, J=15.8,1.6 \mathrm{~Hz}, 1 \mathrm{H}), 7.11(\mathrm{~m}, 4 \mathrm{H}) .{ }^{13} \mathrm{C} \mathrm{NMR}\left(100 \mathrm{MHz}, \mathrm{CDCl}_{3}\right)$ : $\delta_{\mathrm{C}} 14.0,21.1$, 21.8, 23.6, 28.7, 31.7, 39.2, 41.4, 50.7, 119.2, 124.9, 127.7, 135.6, 137.5, 142.8, 152.8, 166.5.

In the racemic variant: Methanesulfonic acid $(4.12 \mathrm{~mL}, 64.3 \mathrm{mmol}, 3$ eq.) was added to a solution of $( \pm)-6\left(7.5 \mathrm{~g}, 21.4 \mathrm{mmol}, 1\right.$ eq.) in $\mathrm{CHCl}_{3}(30 \mathrm{~mL})$ and the reaction mixture was stirred at $40{ }^{\circ} \mathrm{C}$ for two days. The reaction was quenched with saturated $\mathrm{NaHCO}_{3}(50 \mathrm{~mL})$ and extracted with $\mathrm{CH}_{2} \mathrm{Cl}_{2}(3 \times 200 \mathrm{~mL})$. The combined organic layers were dried over $\mathrm{Na}_{2} \mathrm{SO}_{4}$ and concentrated in vacuo. Purification by column chromatography on silica (eluting with 95:5 petroleum ether/ethyl acetate) gave the title compound $( \pm)-7$ as a colourless oil ( $6.4 \mathrm{~g}, 87 \%$ yield).

Methyl $\quad(R)-4-((1 S, 4 R)-4,7$-dimethyl-1,2,3,4-tetrahydronaphthalen-1-yl)pentanoate

$((-)-8)$. Palladium on carbon (10 mol\%) and $\mathrm{NaHCO}_{3}(360 \mathrm{mg}, 4.3 \mathrm{mmol}, 3$ eq.) were added to a solution of alkene $7(0.5 \mathrm{~g}, 1.43 \mathrm{mmol})$ in methanol $(45 \mathrm{~mL})$ and the mixture was pressurized to $30 \mathrm{psi}$ of hydrogen for $3 \mathrm{~h}$. The reaction mixture was then filtered through a pad of celite, washed with diethyl ether and concentrated under reduced pressure to give $(-)-8$ as a clear oil $(0.384 \mathrm{~g}, 98 \%$ yield). ${ }^{1} \mathrm{H}$ NMR $\left(400 \mathrm{MHz}, \mathrm{CDCl}_{3}\right): \delta_{\mathrm{H}} 0.70(\mathrm{~d}, J=6.8 \mathrm{~Hz}, 3 \mathrm{H}), 1.29(\mathrm{~d}, J=6.9 \mathrm{~Hz}, 3 \mathrm{H}), 1.36(\mathrm{~m}$, $1 \mathrm{H}), 1.79(\mathrm{~m}, 4 \mathrm{H}), 1.95(\mathrm{~m}, 1 \mathrm{H}), 2.16(\mathrm{~m}, 1 \mathrm{H}), 2.32(\mathrm{~s}, 3 \mathrm{H}), 2.43(\mathrm{~m}, 2 \mathrm{H}), 2.76(\mathrm{~m}, 1 \mathrm{H}), 2.90(\mathrm{~m}$, 1H), $3.72(\mathrm{~s}, 3 \mathrm{H}) 6.97(\mathrm{~d}, J=7.9 \mathrm{~Hz}, 1 \mathrm{H}), 7.02(\mathrm{~s}, 1 \mathrm{H}), 7.16(\mathrm{~d}, J=7.9 \mathrm{~Hz}, 1 \mathrm{H}) .{ }^{13} \mathrm{C}$ NMR $(100$ $\left.\mathrm{MHz}, \mathrm{CDCl}_{3}\right): \delta_{\mathrm{C}} 13.7,20.5,21.0,21.3,29.7,31.0,32.1,36.5,41.0,50.9,125.6,126.0,127.5$, 134.2, 138.7, 139.8, 173.7. HRMS (ESI) $275.2011\left(\mathrm{C}_{17} \mathrm{H}_{26} \mathrm{O}[\mathrm{M}+\mathrm{H}]^{+}\right.$required 275.2006). $[\alpha]_{\mathrm{D}}{ }^{25}=$ $-37.2\left(\right.$ c $\left.0.1, \mathrm{CHCl}_{3}\right)$.

In the racemic variant: Palladium on carbon $(10 \mathrm{~mol} \%)$ and $\mathrm{NaHCO}_{3}(4.54 \mathrm{~g}, 54 \mathrm{mmol}, 3$ eq.) were added to a solution of alkene $( \pm)-7(6.3 \mathrm{~g}, 18 \mathrm{mmol}, 1$ eq. $)$ in methanol $(400 \mathrm{~mL})$ and the mixture was pressurized to $30 \mathrm{psi}$ of hydrogen for $3 \mathrm{~h}$. The reaction mixture was then filtered through a pad 
of celite, washed with diethyl ether and concentrated under reduced pressure to give ( \pm )-8 as a clear oil ( $4.83 \mathrm{~g}, 98 \%$ yield).

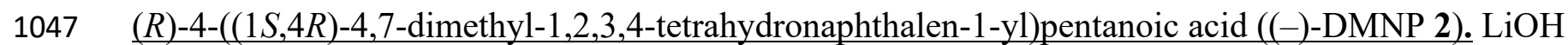
$(96 \mathrm{mg}, 4.0 \mathrm{mmol})$ was added to a solution of ester $8(0.274 \mathrm{~g}, 1.0 \mathrm{mmol})$ in a mixture of THF:MeOH: $\mathrm{H}_{2} \mathrm{O}(2: 1: 1)$. The reaction mixture was heated to $50^{\circ} \mathrm{C}$ for 3 hours, and then allowed to cool to room temperature. A10\% aqueous hydrochloric acid was added dropwise to the reaction mixture until the $\mathrm{pH}$ of the solution reached $\mathrm{pH} 3$. The aqueous layer was then extracted with diethyl ether, dried using $\mathrm{MgSO}_{4}$, filtered and the solvent was removed under reduced pressure to give (-)-DMNP 2 as a light oil $\left(255 \mathrm{mg}, 98 \%\right.$ yield). ${ }^{1} \mathrm{H}$ NMR $\left(400 \mathrm{MHz}, \mathrm{CDCl}_{3}\right): \delta_{\mathrm{H}} 0.72(\mathrm{~d}, J=$ $6.8 \mathrm{~Hz}, 3 \mathrm{H}), 1.31(\mathrm{~d}, J=6.9 \mathrm{~Hz}, 3 \mathrm{H}), 1.37(\mathrm{~m}, 1 \mathrm{H}), 1.95(\mathrm{~m}, 1 \mathrm{H}), 2.19(\mathrm{~m}, 1 \mathrm{H}), 2.332 .48(\mathrm{~m}, J=$ 9.2, 2H), $2.77(\mathrm{~m}, 1 \mathrm{H}), 2.92(\mathrm{~m}, 1 \mathrm{H}), 6.98,7.03(\mathrm{~s}, 1 \mathrm{H}), 7.17(\mathrm{~m}, 1 \mathrm{H}), 9.82$ (br.s., $1 \mathrm{H}) .{ }^{13} \mathrm{C}$ NMR $\left(100 \mathrm{MHz}, \mathrm{CDCl}_{3}\right): \delta_{\mathrm{C}} 13.7,20.5,21.0,21.3,29.4,31.0,32.2,36.4,41.1,125.7,126.0,127.5$, 134.2, 138.6, 139.8, 179.2. HRMS (ESI) $261.1855\left(\mathrm{C}_{17} \mathrm{H}_{25} \mathrm{O}_{2}[\mathrm{M}+\mathrm{H}]^{+}\right.$required 261.1855). $[\alpha]_{\mathrm{D}}{ }^{25}=$ $-29.0\left(c 0.1, \mathrm{CHCl}_{3}\right)$.

In the racemic variant: A solution of ester $( \pm)-8(4.5 \mathrm{~g}, 16.4 \mathrm{mmol})$ was prepared in a mixture of THF:MeOH: $\mathrm{H}_{2} \mathrm{O}(2: 1: 1)$, to which $\mathrm{LiOH}(1.57 \mathrm{~g}, 65.6 \mathrm{mmol})$ was added. The reaction mixture was heated to $50^{\circ} \mathrm{C}$ for 3 hours, and then allowed to cool to room temperature. $10 \%$ aqueous hydrochloric acid was added dropwise to the reaction mixture until the $\mathrm{pH}$ of the solution reached $\mathrm{pH}$ 3. The aqueous layer was then extracted with diethyl ether, dried using $\mathrm{MgSO}_{4}$, filtered and the solvent was removed under reduced pressure to give ( \pm )-DMNP 2 as a light oil ( $4.17 \mathrm{~g}, 98 \%$ yield).

Asymmetric synthesis of (+)-(S)-4-((1S,4R)-4,7-dimethyl-1,2,3,4-tetrahydronaphthalen-1yl)pentanoic acid (+)-(DMNP).

Methyl $(S)$-4-((1R,4S)-4,7-dimethyl-1,2,3,4-tetrahydronaphthalen-1-yl)pentanoate $((+)-8)$ : To a flame dried $25 \mathrm{~mL}$ round bottom flask with a magnetic stir bar was added 1,2-dihydro 1,6dimethylnaphthalene $( \pm)(0.5 \mathrm{~g}, 3.15 \mathrm{mmol})$ and $\mathrm{Rh}_{2}(R \text {-DOSP })_{4}(250.0 \mathrm{mg})$, dissolved in 2,2-DMB $(13 \mathrm{~mL})$ under argon at room temperature. In a $20 \mathrm{~mL}$ syringe a solution of methyl $(E)$-2-diazo-4methyl-3-butenoate $(0.9 \mathrm{~g}, 13 \mathrm{mmol})$ was prepared in 2,2-DMB $(20 \mathrm{~mL})$. The solution of diazo compound was added via syringe pump at a rate of $10 \mathrm{~mL} / \mathrm{h}(\sim 2 \mathrm{~h}$ addition time $)$. After the diazo addition was complete the reaction mixture was allowed to stir for an additional $0.5 \mathrm{~h}$, the solvent was removed under reduced pressure. The crude reaction mixture was taken up in methanol (100 $\mathrm{mL})$ and palladium on carbon $(\mathrm{Pd} / \mathrm{C})(1.0 \mathrm{~g}, 10 \% \mathrm{Pd})$ was added. The reaction mixture was pressurized with $\mathrm{H}_{2}$ gas at $30 \mathrm{psi}$ and allowed to shake for $4 \mathrm{~h}$. The crude mixture was passed through a pad of celite and washed with diethyl ether and concentrated under reduced pressure. Purification by column chromatography $\left(\mathrm{SiO}_{2}\right.$, petroleum ether : ethyl acetate $(99.5: 0.5)$ gave $((+)-$ 8 as a light oil (292 mg $34 \%$ yield, over 2 step): ${ }^{1} \mathrm{H}$ NMR $\left(400 \mathrm{MHz}, \mathrm{CDCl}_{3}\right): \delta_{\mathrm{H}} 0.70(\mathrm{~d}, J=6.8$ $\mathrm{Hz}, 3 \mathrm{H}), 1.29(\mathrm{~d}, J=6.9 \mathrm{~Hz}, 3 \mathrm{H}), 1.36(\mathrm{~m}, 1 \mathrm{H}), 1.79(\mathrm{~m}, 4 \mathrm{H}), 1.95(\mathrm{~m}, 1 \mathrm{H}), 2.16(\mathrm{~m}, 1 \mathrm{H}), 2.32(\mathrm{~s}$, $3 \mathrm{H}), 2.43(\mathrm{~m}, 2 \mathrm{H}), 2.76(\mathrm{~m}, 1 \mathrm{H}), 2.90(\mathrm{~m}, 1 \mathrm{H}), 3.72(\mathrm{~s}, 3 \mathrm{H}) 6.97(\mathrm{~d}, J=7.9 \mathrm{~Hz}, 1 \mathrm{H}), 7.02(\mathrm{~s}, 1 \mathrm{H})$, $7.16(\mathrm{~d}, J=7.9 \mathrm{~Hz}, 1 \mathrm{H}) .{ }^{13} \mathbf{C}$ NMR $\left(100 \mathrm{MHz}, \mathrm{CDCl}_{3}\right): \delta_{\mathrm{C}} 13.7,20.5,21.0,21.3,29.7,31.0,32.1$, 36.5, 41.0, 50.9, 125.6, 126.0, 127.5, 134.2, 138.7, 139.8, 173.7. HRMS (ESI) 275.2011 $\left(\mathrm{C}_{17} \mathrm{H}_{26} \mathrm{O}\right.$ $[\mathrm{M}+\mathrm{H}]^{+}$required 275.2006). $[\alpha]_{\mathrm{D}}^{25}=+37.2\left(c 0.1, \mathrm{CHCl}_{3}\right)$. solution of ester $(+)-8(0.274 \mathrm{~g}, 1.0 \mathrm{mmol})$ was prepared in a mixture of THF:MeOH:H2O (2:1:1), to which $\mathrm{LiOH}\left(96 \mathrm{mg}, 4.0 \mathrm{mmol}\right.$ ) was added. The reaction mixture was heated to $50^{\circ} \mathrm{C}$ for 3 hours, and then allowed to cool to room temperature. A $10 \%$ aqueous hydrochloric acid was added dropwise to the reaction mixture until the $\mathrm{pH}$ of the solution reached $\mathrm{pH}$ 3. The aqueous layer was then extracted with diethyl ether, dried over $\mathrm{MgSO}_{4}$, filtered and the solvent was removed under reduced pressure to give (+)-DMNP 2 as a light oil $\left(255 \mathrm{mg}, 98 \%\right.$ yield). ${ }^{1} \mathrm{H}$ NMR (400 MHz, $\left.\mathrm{CDCl}_{3}\right): \delta_{\mathrm{H}} 0.72(\mathrm{~d}, J=6.8 \mathrm{~Hz}, 3 \mathrm{H}), 1.31(\mathrm{~d}, J=6.9 \mathrm{~Hz}, 3 \mathrm{H}), 1.37(\mathrm{~m}, 1 \mathrm{H}), 1.95(\mathrm{~m}, 1 \mathrm{H}), 2.19(\mathrm{~m}$, 1H), $2.332 .48(\mathrm{~m}, J=9.2,2 \mathrm{H}), 2.77(\mathrm{~m}, 1 \mathrm{H}), 2.92(\mathrm{~m}, 1 \mathrm{H}), 6.98,7.03(\mathrm{~s}, 1 \mathrm{H}), 7.17(\mathrm{~m}, 1 \mathrm{H}), 9.82$ 
$1095125.7,126.0,127.5,134.2,138.6,139.8,179.2$. HRMS (ESI) $261.1855\left(\mathrm{C}_{17} \mathrm{H}_{25} \mathrm{O}_{2}[\mathrm{M}+\mathrm{H}]^{+}\right.$ 1096 required 261.1855). $[\alpha]_{\mathrm{D}}{ }^{25}=+29.0\left(c 0.1, \mathrm{CHCl}_{3}\right)$.

\section{Quantification and Statistical Analysis}

1099 Statistica for Windows 5.0 (StatSoft, Inc., 1995) software was used for processing of the 1100 experimental data, presented as mean \pm SEM; $n$ equals the number of assay replicates (independent 1101 experiments). Statistical significance of the differences between the mean values of the compared 1102 groups was assessed by the unpaired Student's $t$-test. The differences were considered significant at $1103 p<0.05$ 
The authors declare no competing interests.

1106

\section{References}

1108

1109

1110

1111

1112

1113

1114

1115

1116

1117

1118

1119

1120

1121

1122

1123

1124

1125

1126

1127

1128

1129

1130

1131

1132

1133

1134

Akhova, A.V., and Tkachenko, A.G. (2019). HPLC-UV method for simultaneous determination of adenosine triphosphate and its metabolites in Mycobacterium smegmatis. Acta Chromatographica $31,45-48$.

Arai, M., Kamiya, K., Pruksakorn, P., Sumii, Y., Kotoku, N., Joubert, J.P., Moodley, P., Han, C., Shin, D., and Kobayashi, M. (2015). Anti-dormant mycobacterial activity and target analysis of nybomycin produced by a marine-derived Streptomyces sp. Bioorganic \& medicinal chemistry 23, 3534-3541.

Arai, M., Yamano, Y., Setiawan, A., and Kobayashi, M. (2014). Identification of the Target Protein of Agelasine D, a Marine Sponge Diterpene Alkaloid, as an Anti-dormant Mycobacterial Substance. ChemBioChem 15, 117-123.

Atkinson, G.C., Tenson, T., and Hauryliuk, V. (2011). The RelA/SpoT homolog (RSH) superfamily: distribution and functional evolution of ppGpp synthetases and hydrolases across the tree of life. PLoS One 6, e23479.

Balaban, N.Q., Helaine, S., Lewis, K., Ackermann, M., Aldridge, B., Andersson, D.I., Brynildsen, M.P., Bumann, D., Camilli, A., Collins, J.J., et al. (2019). Definitions and guidelines for research on antibiotic persistence. Nature Reviews Microbiology.

Bayer, M.E., and Sloyer, J.L., Jr. (1990). The electrophoretic mobility of gram-negative and grampositive bacteria: an electrokinetic analysis. Journal of general microbiology 136, 867-874.

Blokpoel, M.C.J., Murphy, H.N., O'Toole, R., Wiles, S., Runn, E.S.C., Stewart, G.R., Young, D.B., and Robertson, B.D. (2005). Tetracycline-inducible gene regulation in mycobacteria. Nucleic acids research 33, e22.

Brauner, A., Fridman, O., Gefen, O., and Balaban, N.Q. (2016). Distinguishing between resistance, tolerance and persistence to antibiotic treatment. Nat Rev Micro 14, 320-330.

Brown, A., Fernandez, I.S., Gordiyenko, Y., and Ramakrishnan, V. (2016). Ribosome-dependent activation of stringent control. Nature 534, 277-280.

Camacho, C., Coulouris, G., Avagyan, V., Ma, N., Papadopoulos, J., Bealer, K., and Madden, T.L. (2009). BLAST+: architecture and applications. BMC Bioinformatics 10, 421. 
Ceri, H., Olson, M.E., Stremick, C., Read, R.R., Morck, D., and Buret, A. (1999). The Calgary Biofilm Device: new technology for rapid determination of antibiotic susceptibilities of bacterial biofilms. Journal of clinical microbiology 37, 1771-1776.

Chapman, A.G., and Atkinson, D.E. (1977). Adenine nucleotide concentrations and turnover rates. Their correlation with biological activity in bacteria and yeast. Adv Microb Physiol. 15, 253-306. Coligan, J.E. (1996). Current protocols in protein science, edited by J.E. Coligan, B.M. Dunn, H.L. Ploegh, D.W. Speicher, and P.T. Wingfield. New York: Wiley. (New York, Wiley Subscription Services, Inc., A Wiley Company), p. 864.

Davies, H. M. L., and Walji, A. M. (2005). Direct Synthesis of (+)-Erogorgiaene through a kinetic enantiodifferentiating step. Anwewandte Chemie International Edition 44, 1733-1735.

Dong, D., Wang, D., Li, M., Wang, H., Yu, J., Wang, C., Liu, J., and Gao, Q. (2012). PPE38 modulates the innate immune response and is required for Mycobacterium marinum virulence. Infect Immun 80, 43-54.

Esteban, J., and Garcia-Coca, M. (2017). Mycobacterium Biofilms. Frontiers in microbiology 8 , 2651.

Garrison, A.T., and Huigens, R.W. (2017). Eradicating Bacterial Biofilms with Natural Products and Their Inspired Analogues that Operate Through Unique Mechanisms. Curr Top Med Chem 17, $1-11$.

Gefen, O., Fridman, O., Ronin, I., and Balaban, N.Q. (2014). Direct observation of single stationary-phase bacteria reveals a surprisingly long period of constant protein production activity. Proceedings of the National Academy of Sciences of the United States of America 111, 556-561. Gupta, K.R., Baloni, P., Indi, S.S., and Chatterji, D. (2016). Regulation of Growth, Cell Shape, Cell Division, and Gene Expression by Second Messengers (p)ppGpp and Cyclic Di-GMP in Mycobacterium smegmatis. Journal of bacteriology 198, 1414-1422.

Gupta, K.R., Kasetty, S., and Chatterji, D. (2015). Novel Functions of (p)ppGpp and Cyclic diGMP in Mycobacterial Physiology Revealed by Phenotype Microarray Analysis of Wild-Type and Isogenic Strains of Mycobacterium smegmatis. Applied and Environmental Microbiology 81, 25712578 .

Incerti-Pradillos, C.A., Kabeshov, M.A., O'Hora, P.S., Shipilovskikh, S.A., Rubtsov, A.E., Drobkova, V.A., Balandina, S.Y., and Malkov, A.V. (2016). Asymmetric Total Synthesis of (-)Erogorgiaene and Its C-11 Epimer and Investigation of Their Antimycobacterial Activity. Chemistry - A European Journal 22, 14390-14396.

Jimmy, S., Saha, C.K., Kurata, T., Stavropoulos, C., Oliveira, S.R.A., Koh, A., Cepauskas, A., Takada, H., Rejman, D., Tenson, T., et al. (2020). A widespread toxin-antitoxin system exploiting 
growth control via alarmone signaling. Proceedings of the National Academy of Sciences of the United States of America 117, 10500-10510.

Keren, I., Shah, D., Spoering, A., Kaldalu, N., and Lewis, K. (2004). Specialized Persister Cells and the Mechanism of Multidrug Tolerance in Escherichia coli. Journal of bacteriology 186, 8172-8180. Ko, J., Park, H., and Seok, C. (2012). GalaxyTBM: template-based modeling by building a reliable core and refining unreliable local regions. BMC Bioinformatics 13, 198.

Kolter, R., Siegele, D.A., and Tormo, A. (1993). The stationary phase of the bacterial life cycle. Annual review of microbiology 47, 855-874.

Krasny, L., and Gourse, R.L. (2004). An alternative strategy for bacterial ribosome synthesis: Bacillus subtilis rRNA transcription regulation. Embo j 23, 4473-4483.

Kushwaha, G.S., Oyeyemi, B.F., and Bhavesh, N.S. (2019). Stringent response protein as a potential target to intervene persistent bacterial infection. Biochimie 165, 67-75.

Lange, R., and Hengge-Aronis, R. (1994). The cellular concentration of the sigma S subunit of RNA polymerase in Escherichia coli is controlled at the levels of transcription, translation, and protein stability. Genes and Development $8,1600-1612$.

Larkin, M.A., Blackshields, G., Brown, N.P., Chenna, R., McGettigan, P.A., McWilliam, H., Valentin, F., Wallace, I.M., Wilm, A., Lopez, R., et al. (2007). Clustal W and Clustal X version 2.0. Bioinformatics 23, 2947-2948.

Lewis, K. (2010). Persister cells. Annual review of microbiology 64, 357-372.

Manav, M.C., Beljantseva, J., Bojer, M.S., Tenson, T., Ingmer, H., Hauryliuk, V., and Brodersen, D.E. (2018). Structural basis for (p)ppGpp synthesis by the Staphylococcus aureus small alarmone synthetase RelP. J Biol Chem 293, 3254-3264.

Miller, J.H. (1972). Experiments in molecular genetics, Vol 60 (Cold Spring Harbor Laboratory Cold Spring Harbor, New York).

Mittenhuber, G. (2001). Comparative genomics and evolution of genes encoding bacterial (p)ppGpp synthetases/hydrolases (the Rel, RelA and SpoT proteins). J Mol Microbiol Biotechnol 3, 585-600. Pacios, O., Blasco, L., Bleriot, I., Fernandez-Garcia, L., Ambroa, A., López, M., Bou, G., Cantón, R., Garcia-Contreras, R., Wood, T.K., et al. (2020). (p)ppGpp and Its Role in Bacterial Persistence: New Challenges. Antimicrobial agents and chemotherapy 64.

Parish, T., and Stoker, N.G. (2000). Use of a flexible cassette method to generate a double unmarked Mycobacterium tuberculosis tlyA plcABC mutant by gene replacement. Microbiology 146 ( Pt 8), 1969-1975.

Petchiappan, A., Naik, S.Y., and Chatterji, D. (2020). RelZ-Mediated Stress Response in Mycobacterium smegmatis: pGpp Synthesis and Its Regulation. Journal of bacteriology 202. 
1203

1204

1205

1206

1207

1208

1209

1210

1211

1212

1213

1214

1215

1216

1217

1218

1219

1220

1221

1222

1223

1224

1225

1226

1227

1228

1229

1230

1231

1232

1233

1234

Primm, T.P., Andersen, S.J., Mizrahi, V., Avarbock, D., Rubin, H., and Barry, C.E., 3rd (2000).

The stringent response of Mycobacterium tuberculosis is required for long-term survival. Journal of bacteriology 182, 4889-4898.

Prossliner, T., Skovbo Winther, K., Sorensen, M.A., and Gerdes, K. (2018). Ribosome Hibernation. Annu Rev Genet 52, 321-348.

Prusa, J., Zhu, D.X., and Stallings, C.L. (2018). The stringent response and Mycobacterium tuberculosis pathogenesis. Pathogens and disease 76.

Rao, N.N., Gomez-Garcia, M.R., and Kornberg, A. (2009). Inorganic polyphosphate: essential for growth and survival. Annu Rev Biochem 78, 605-647.

Rodríguez, A.D., and Ramírez, C. (2001). Serrulatane Diterpenes with Antimycobacterial Activity Isolated from the West Indian Sea Whip Pseudopterogorgia elisabethae. Journal of Natural Products 64, 100-102.

Rosenberg, M. (2006). Microbial adhesion to hydrocarbons: twenty-five years of doing MATH. FEMS microbiology letters 262, 129-134.

Salentin, S., Schreiber, S., Haupt, V.J., Adasme, M.F., and Schroeder, M. (2015). PLIP: fully automated protein-ligand interaction profiler. Nucleic acids research 43, W443-447.

Sanchez-Linares, I., Perez-Sanchez, H., Cecilia, J.M., and Garcia, J.M. (2012). High-Throughput parallel blind Virtual Screening using BINDSURF. BMC Bioinformatics 13 Suppl 14, S13.

Sato, S., Murata, A., Shirakawa, T., and Uesugi, M. (2010). Biochemical target isolation for novices: affinity-based strategies. Chem Biol 17, 616-623.

Shan, Y., Brown Gandt, A., Rowe, S.E., Deisinger, J.P., Conlon, B.P., and Lewis, K. (2017). ATPDependent Persister Formation in Escherichia coli. MBio 8.

Sharma, D., Misba, L., and Khan, A.U. (2019). Antibiotics versus biofilm: an emerging battleground in microbial communities. Antimicrob Resist Infect Control 8, 76.

Sharma, I.M., Petchiappan, A., and Chatterji, D. (2014). Quorum sensing and biofilm formation in mycobacteria: Role of c-di-GMP and methods to study this second messenger. IUBMB Life 66, 823-834.

Singal, B., Balakrishna, A.M., Nartey, W., Manimekalai, M.S.S., Jeyakanthan, J., and Gruber, G. (2017). Crystallographic and solution structure of the N-terminal domain of the Rel protein from Mycobacterium tuberculosis. FEBS Lett 591, 2323-2337.

Steinchen, W., and Bange, G. (2016). The magic dance of the alarmones (p)ppGpp. Mol Microbiol $101,531-544$. 
1235 Syal, K., Bhardwaj, N., and Chatterji, D. (2017). Vitamin C targets (p)ppGpp synthesis leading to

1236 stalling of long-term survival and biofilm formation in Mycobacterium smegmatis. FEMS

1237 microbiology letters 364.

1238 T, J.A.S., J, R., Rajan, A., and Shankar, V. (2020). Features of the biochemistry of Mycobacterium 1239 smegmatis, as a possible model for Mycobacterium tuberculosis. J Infect Public Health 13, 125512401264.

1241 Torrey, H.L., Keren, I., Via, L.E., Lee, J.S., and Lewis, K. (2016). High persister mutants in 1242 Mycobacterium tuberculosis. PLoS ONE 11, e0155127.

1243 Trott, O., and Olson, A.J. (2010). AutoDock Vina: improving the speed and accuracy of docking 1244 with a new scoring function, efficient optimization, and multithreading. Journal of computational 1245 chemistry $31,455-461$.

1246 Wexselblatt, E., Katzhendler, J., Saleem-Batcha, R., Hansen, G., Hilgenfeld, R., Glaser, G., and 1247 Vidavski, R.R. (2010). ppGpp analogues inhibit synthetase activity of Rel proteins from Gram1248 negative and Gram-positive bacteria. Bioorganic \& medicinal chemistry 18, 4485-4497.

1249 Wexselblatt, E., Oppenheimer-Shaanan, Y., Kaspy, I., London, N., Schueler-Furman, O., Yavin, E., 1250 Glaser, G., Katzhendler, J., and Ben-Yehuda, S. (2012). Relacin, a novel antibacterial agent 1251 targeting the Stringent Response. PLoS pathogens 8, e1002925.

1252 Williams, K.J., Joyce, G., and Robertson, B.D. (2010). Improved mycobacterial tetracycline 1253 inducible vectors. Plasmid 64, 69-73. 
Figure 1
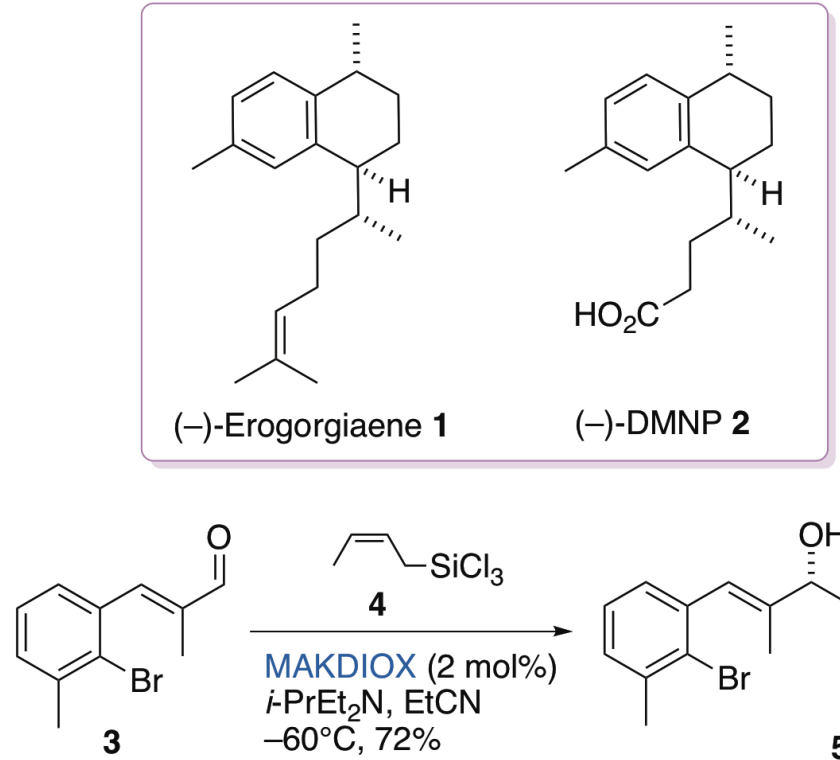

3 i-PrEt $2 \mathrm{~N}, \mathrm{EtCN}$ $-60^{\circ} \mathrm{C}, 72 \%$

1) $\mathrm{LiOH}$ THF:MeOH: $\mathrm{H}_{2} \mathrm{O}(2: 1: 1)$ $50^{\circ} \mathrm{C}, 3 \mathrm{~h}$

(-)-DMNP 2<smiles>C=C[C@H](C)[C@@H](O)/C(C)=C/c1cccc(C)c1Br</smiles>

5

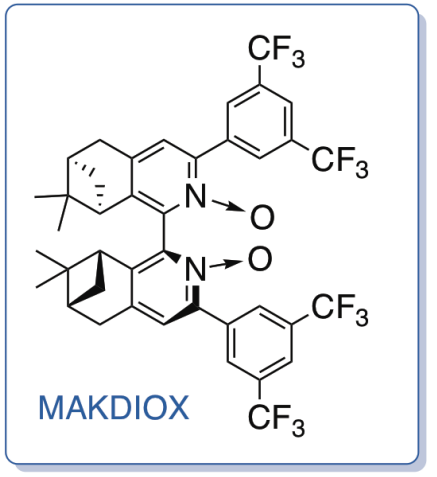

1i) $\mathrm{KH},[18] \mathrm{C}-6$, rt ii) $\mathrm{ArOH},-78^{\circ} \mathrm{C}$<smiles>COC(=O)CC(=O)OC</smiles>
$51 \%$ yield over two steps
6

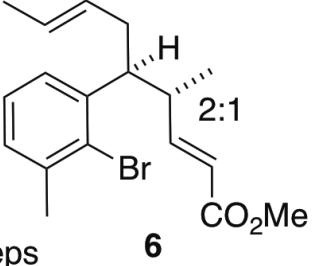

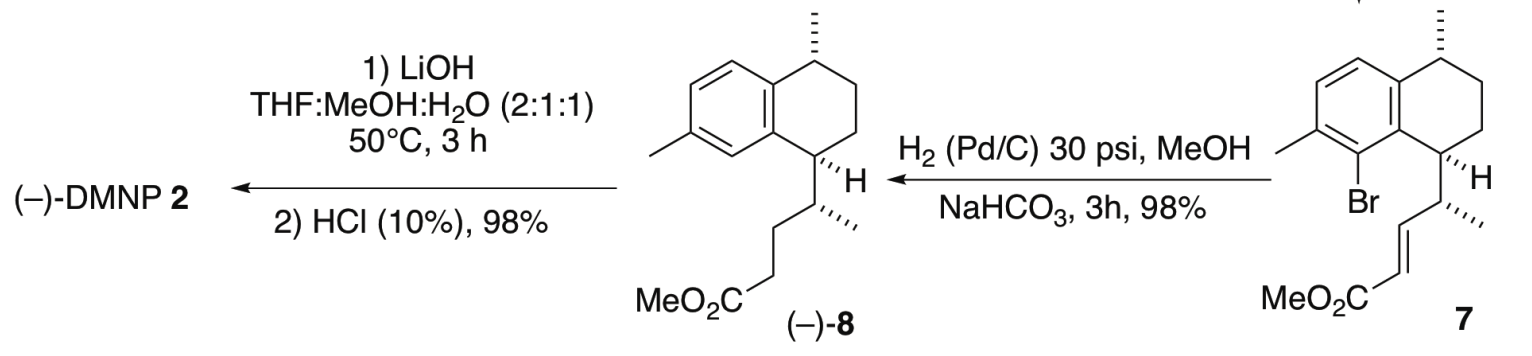


Figure 2

A
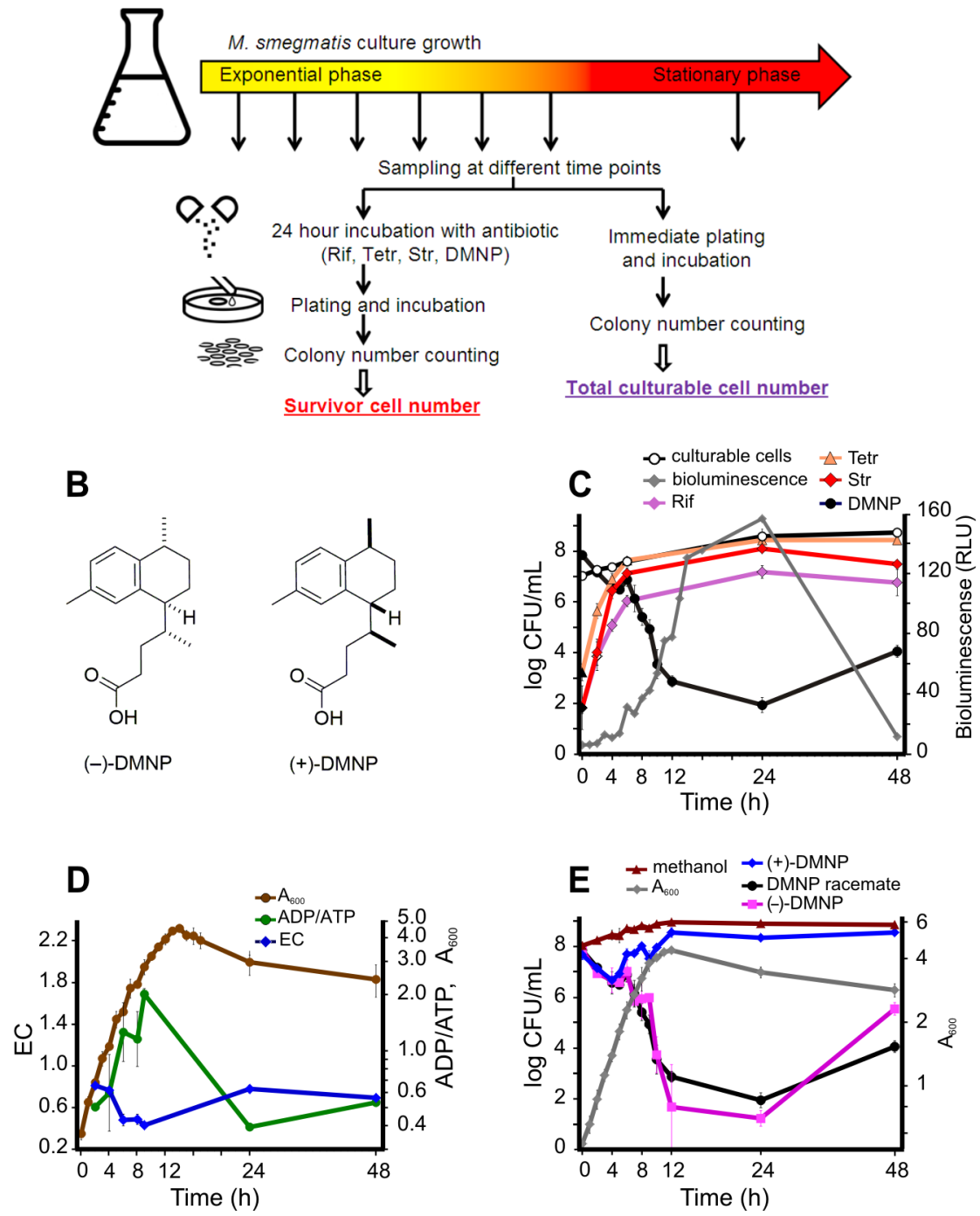
Figure 3

A

EXPONENTIAL PHASE CELLS

STATIONARY PHASE CELLS

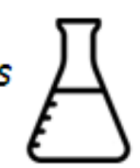

Sampling at 2 time points

\section{Exponential Stationary}

phase

phase

cells

cells

Cell incubation

O.: 0

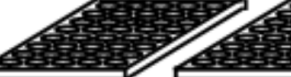

with or without antibiotic

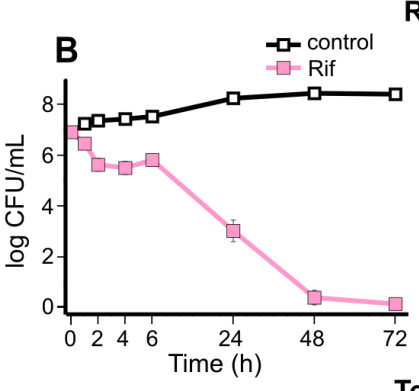

Rifampicin
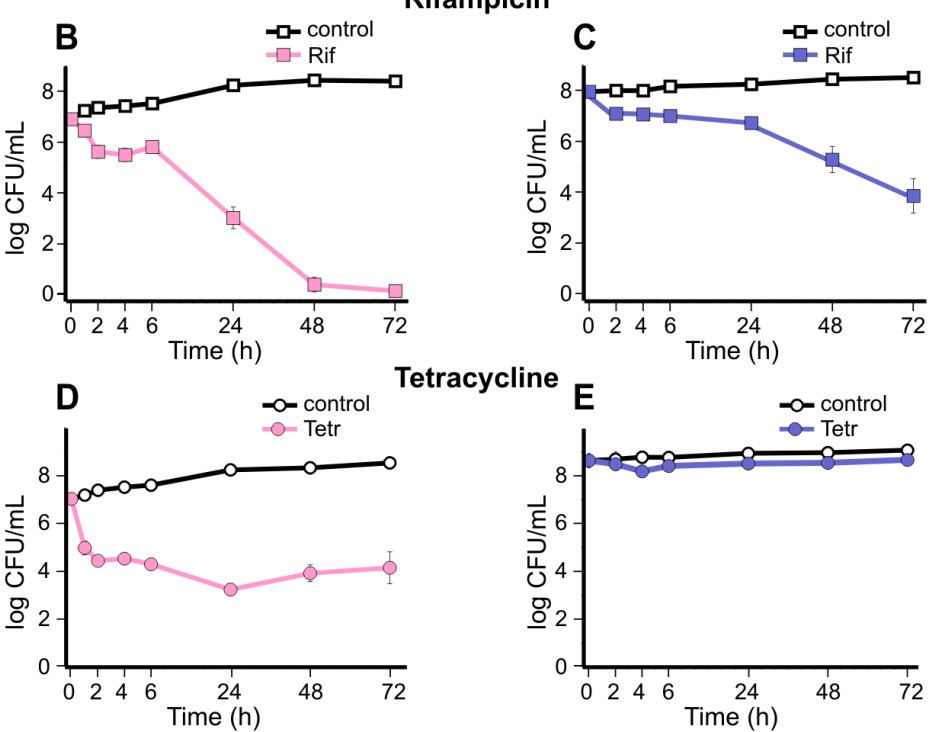

Tetracycline
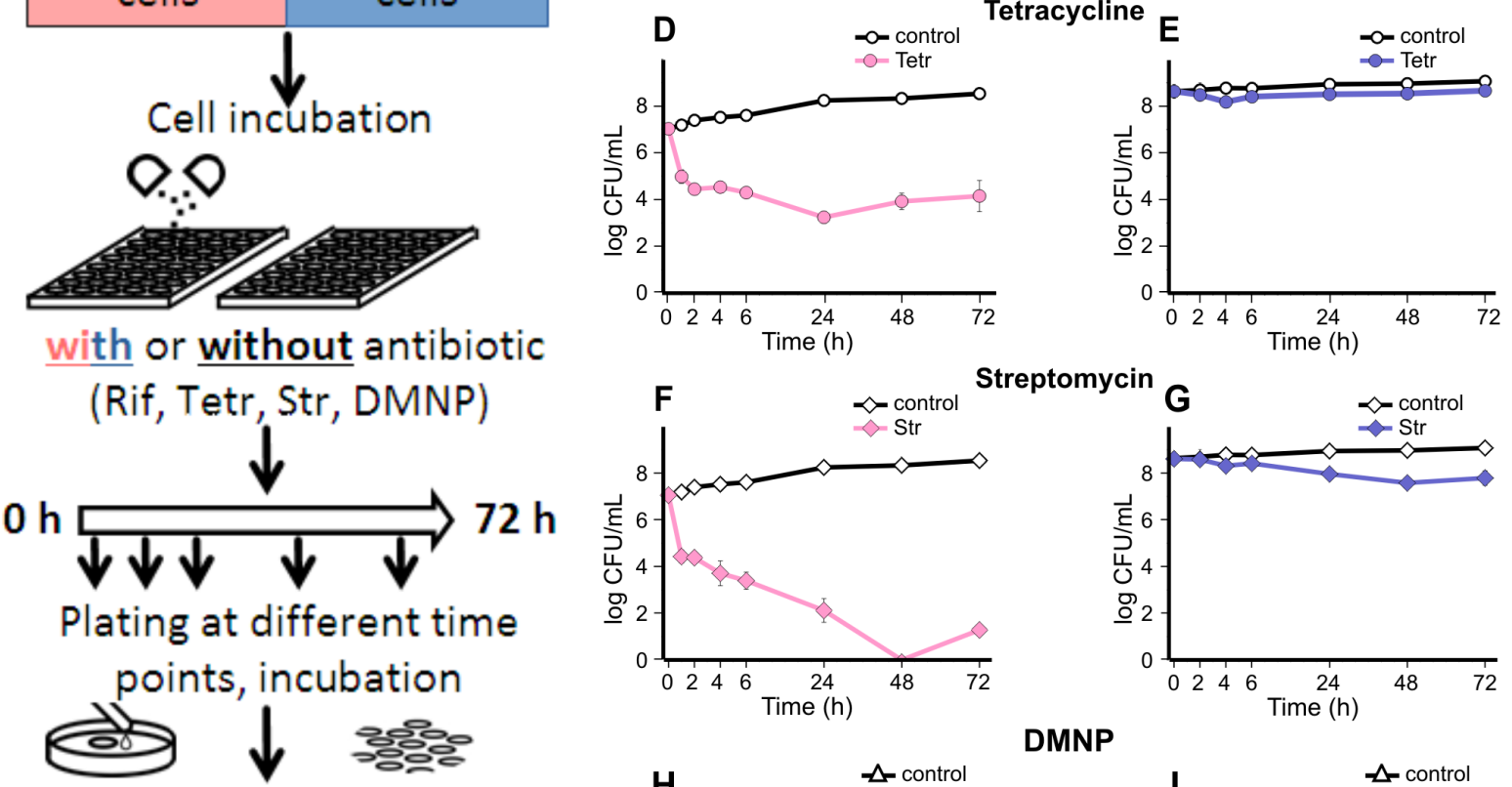

Colony number counting<smiles>[CH]1C=C1</smiles>

Untreated and survivor cell number

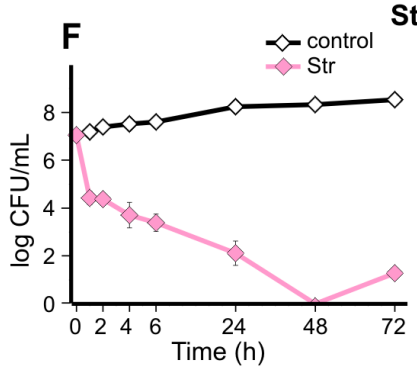

Streptomycin $\mathbf{G}$

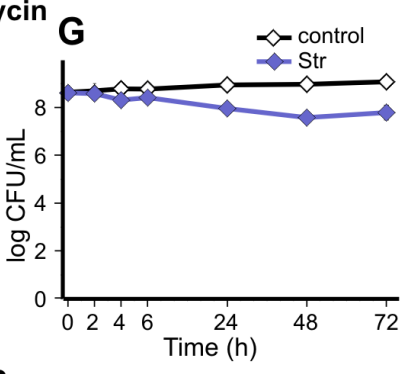

DMNP
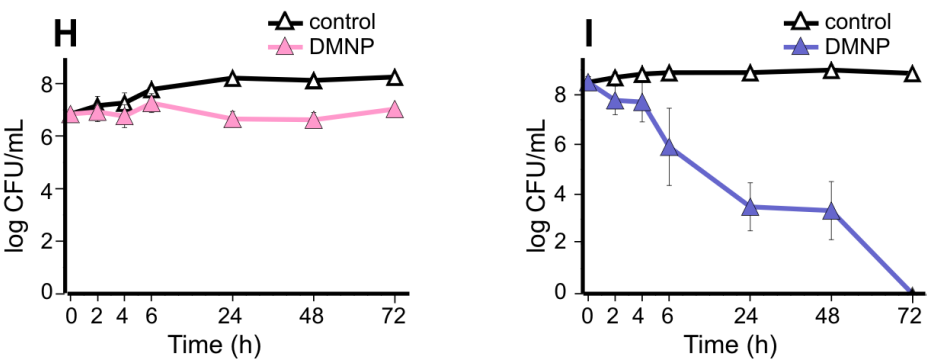
Figure 4

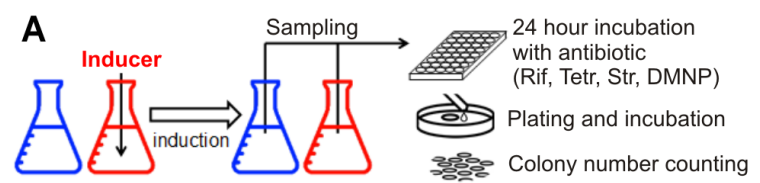

\begin{tabular}{|c|c|c|c|c|}
\hline \multirow{2}{*}{$\begin{array}{l}\text { Strain } \\
\mathrm{mc}^{2} \mathrm{pMind}-0\end{array}$} & \multicolumn{3}{|c|}{$\begin{array}{l}\text { Cell profile of } \\
\text { targeted proteins }\end{array}$} & \multirow{2}{*}{$\begin{array}{l}\begin{array}{l}\text { Survival of cells } \\
\text { exposed to DMNP }\end{array} \\
\text { normal }\end{array}$} \\
\hline & $\operatorname{Rel}_{\mathrm{msm}}$ & RelZ & other & \\
\hline \multirow{2}{*}{$\mathrm{mc}^{2} \mathrm{pMind}-\mathrm{re} \mathrm{I}_{\mathrm{Msm}}$} & $\operatorname{Rel}_{\mathrm{Msm}^{+}}+$ & & & \multirow{2}{*}{ increased } \\
\hline & $\operatorname{ReI}_{\mathrm{msm}}$ & RelZ & other & \\
\hline \multirow{2}{*}{$\mathrm{mc}^{2} \mathrm{pMind}-\mathrm{re} / Z$} & & RelZ+ & & \multirow{2}{*}{ increased } \\
\hline & $\operatorname{Rel}_{\mathrm{msm}}$ & RelZ & other & \\
\hline $\mathrm{mc}^{2} \Delta r e /_{\text {Msm }} \mathrm{pMind}-0$ & $\mathrm{Re}_{\mathrm{Msm}}$ & RelZ & other & decreased \\
\hline $\mathrm{mc}^{2} \Delta r e I_{\text {Msm }} \Delta r e / Z$ pMind-0 & $\mathrm{ReI}_{\mathrm{Msm}}$ & Retz & other & further decreased \\
\hline \multirow{2}{*}{$\mathrm{mc}^{2} \Delta r e I_{\mathrm{Msm}} \mathrm{pMind}-r e I_{\mathrm{Msm}}$} & $\operatorname{Rel}_{\mathrm{Msm}^{+}}$ & & & \multirow{2}{*}{ complemented } \\
\hline & Ret & RelZ & other & \\
\hline \multirow{2}{*}{$\mathrm{mc}^{2} \Delta r e I_{\text {Msm }}$ pMind-relZ } & & RelZ+ & & \multirow{2}{*}{ complemented } \\
\hline & Rethsm & RelZ & other & \\
\hline \multirow{2}{*}{$\begin{array}{l}\mathrm{mc}^{2} \Delta r e I_{\text {Msm }} \Delta r e l Z \\
\text { pMind-rel } I_{\text {Msm }}\end{array}$} & $\operatorname{Rel}_{\mathrm{Msm}^{+}}+$ & & & \multirow{2}{*}{ complemented } \\
\hline & $\mathrm{Ret}_{\mathrm{Msm}}$ & Retz & other & \\
\hline \multirow{2}{*}{$\begin{array}{l}\mathrm{mc}^{2} \Delta r e I_{\text {Msm }} \Delta r e l Z \\
\text { pMind-relZ }\end{array}$} & & RelZ+ & & \multirow{2}{*}{ complemented } \\
\hline & 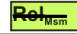 & Retz & other & \\
\hline
\end{tabular}
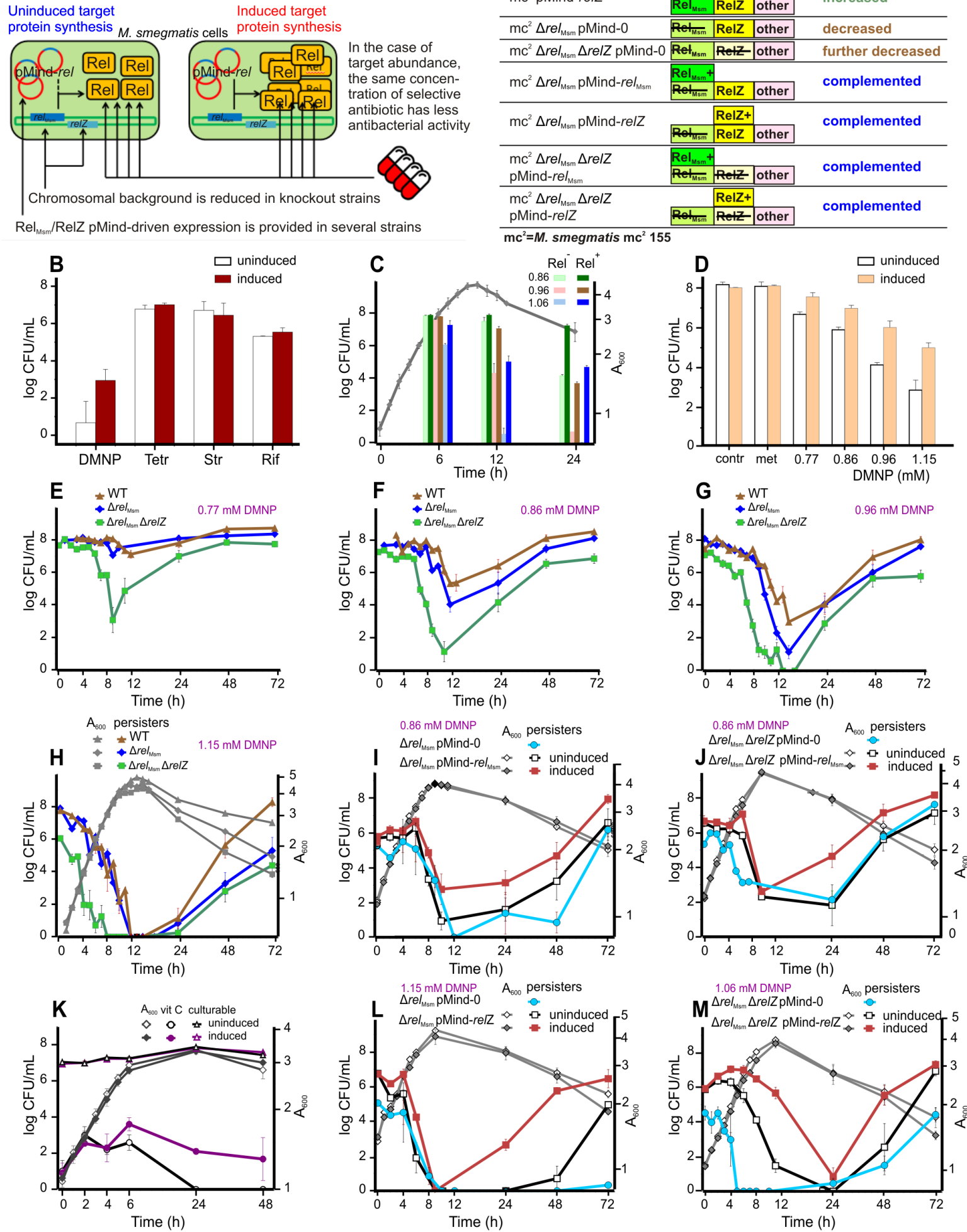
Figure 5
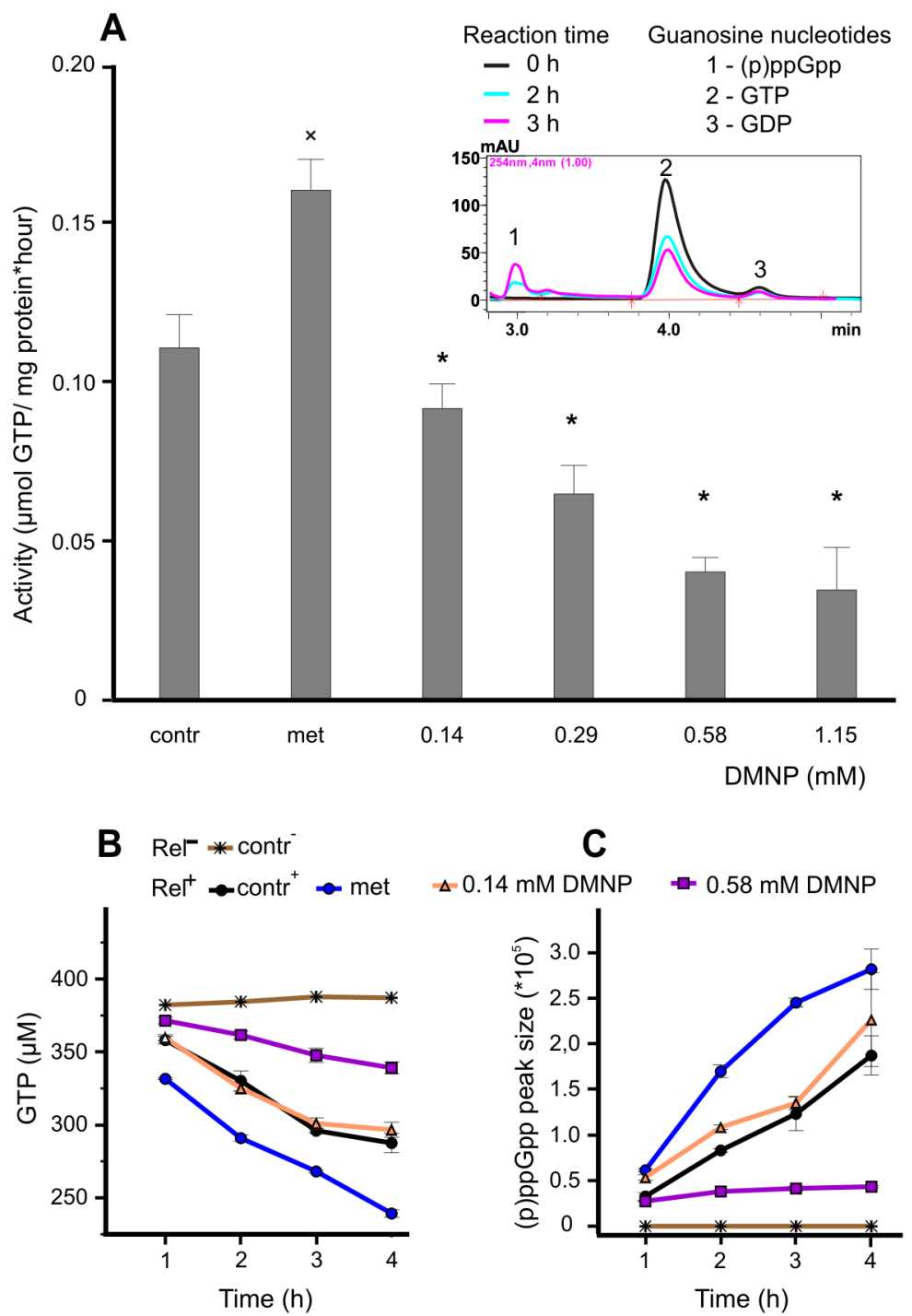

\section{C}

$\Delta 0.14 \mathrm{mM}$ DMNP $\quad \square 0.58 \mathrm{mM}$ DMNP

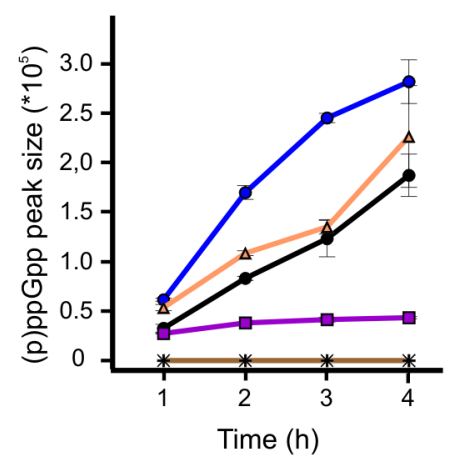


Figure 6

A

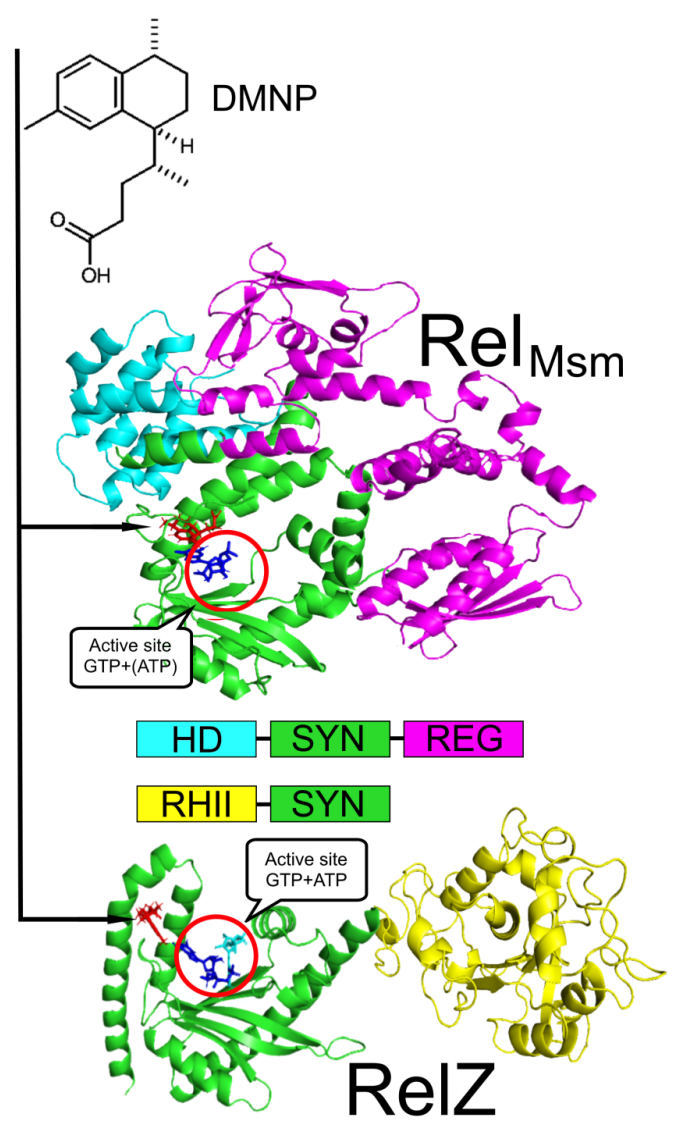

E

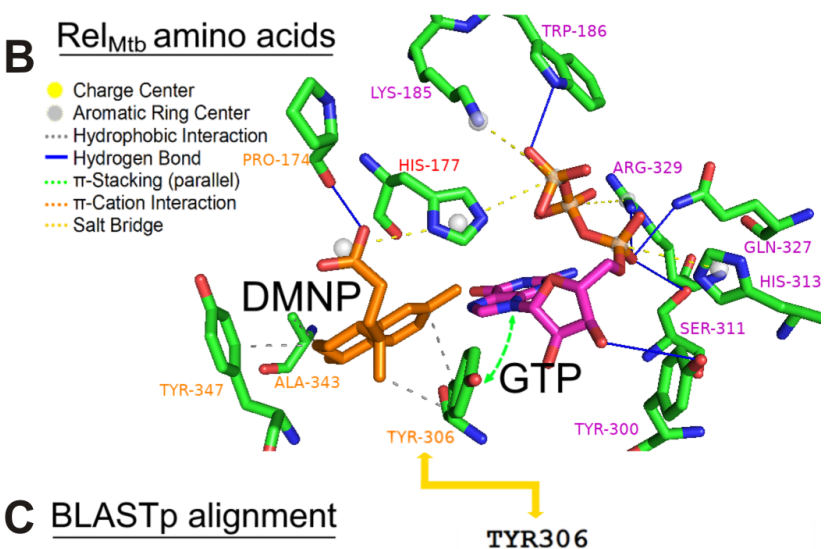

RelMtb 293 MAGRFKDYIAQPRÝGVYQSLHTTVVGP 319

$$
+\mathrm{KDYI} \mathrm{P}+\mathrm{Y}+\mathrm{SLH} \mathrm{V} \text { P }
$$

SAS2Saur 135 QLIKRKDYIQHPKENGYRSLHIVVSIP 161

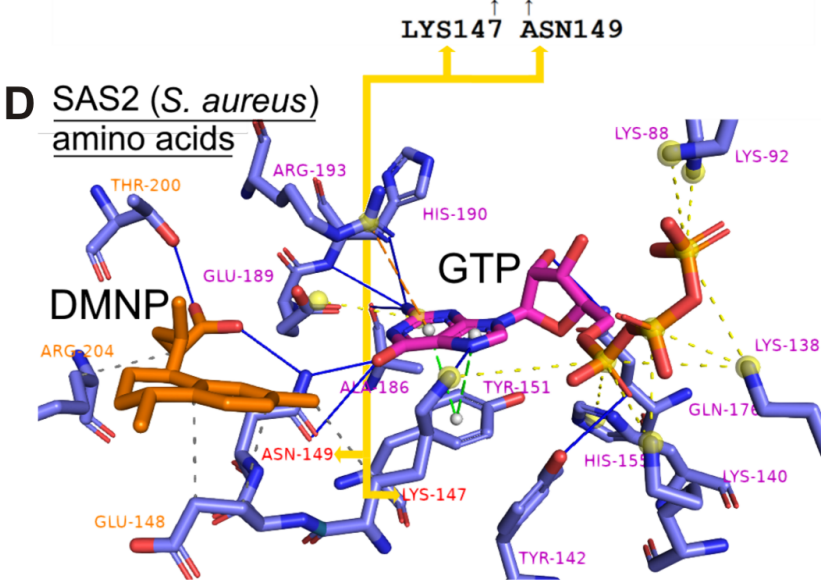

Syn3 site

(binds GDP/GTP)
Syn4 site

(binds ATP \& Mg)

RelMsm 348 $\rightarrow$ LWQPMAGRFKDYIAQPRYGVYQSLHTTVVGPEGKPLEVQIRT $\leftarrow 389$

RelMtb $289 \rightarrow$ LWPMAGRFKDYIAQPRYGVYQSLHTTVVGPEGKPLEVQIRT $\leftarrow 330$

RelSeq $288 \rightarrow$ LWRPMPRFKDYIAAPKANGYQS IHTTVYGPKG PIEIQIRT $\leftarrow 328$ 
Figure 7
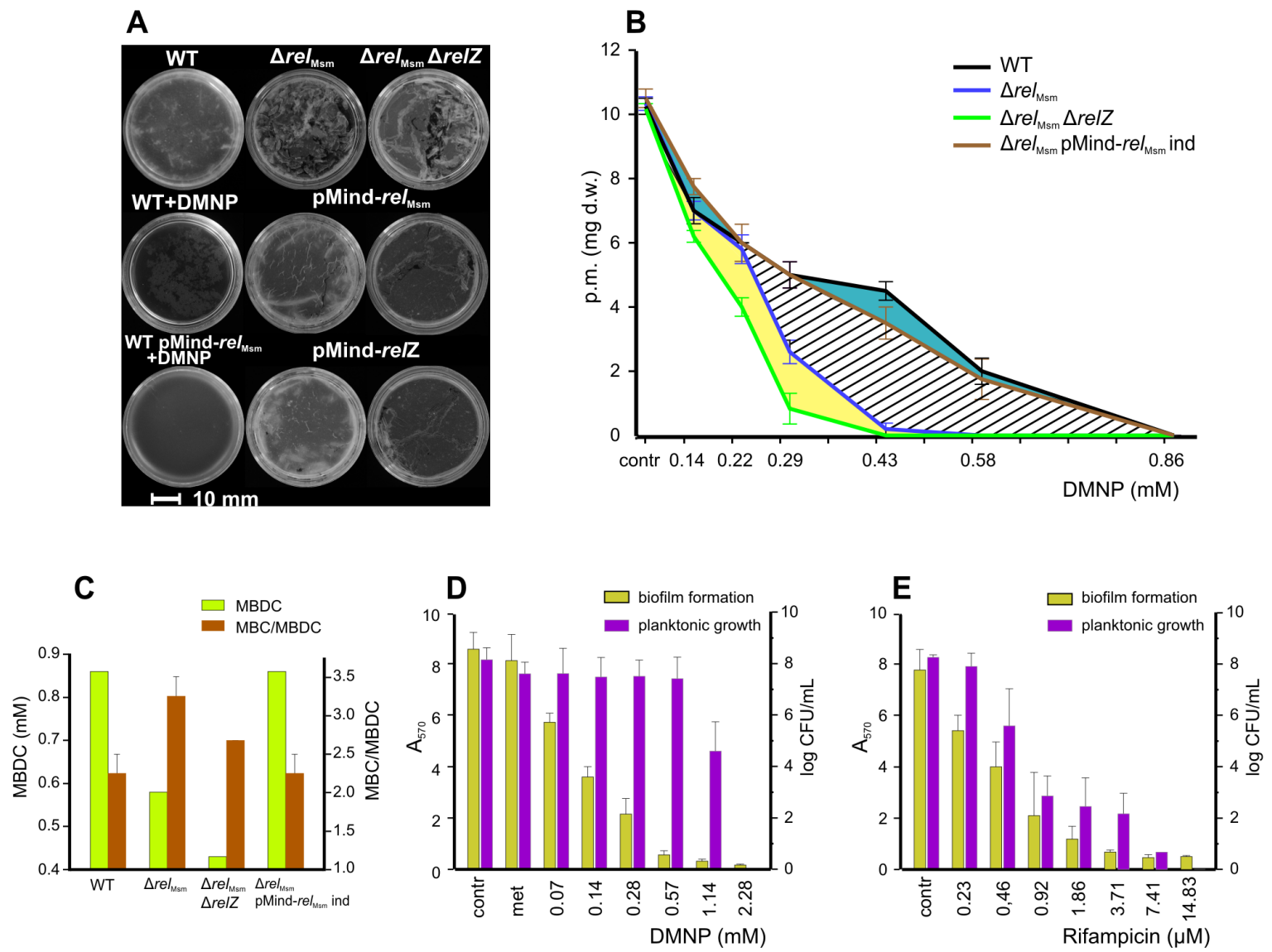

F

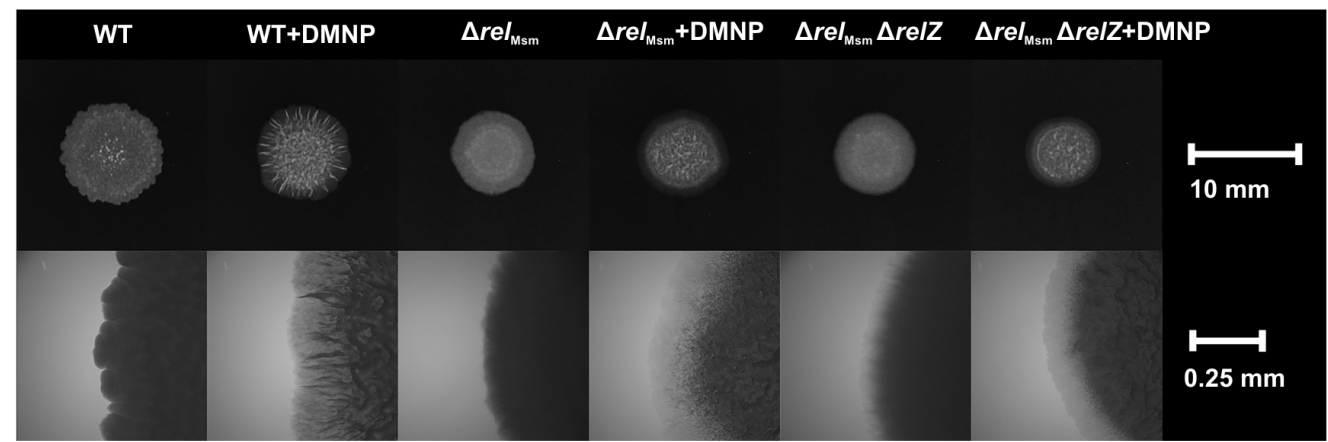

G

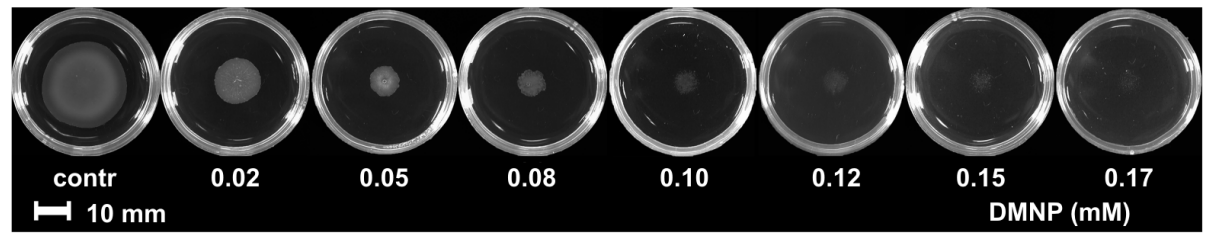

